\title{
ARQUEOLOGÍA DE SUPERFICIE EN LA CUENCA LACUSTRE DEL TAMESI, HUASTECA SEPTENTRIONAL Evidencias de la Dinámica Paleo Poblacional y Aprovechamiento del Espacio
}

\author{
SURFACE ARCHEOLOGY IN THE LACUSTRE BASIN OF \\ TAMESI, NORTHERN HUASTECA \\ Evidence of the Paleo-population Dynamic and Use of Space
}

\author{
Gustavo A. Ramírez Castilla ${ }^{1}$
}

gustavo_ramirez@inah.gob.mx

\section{RESUMEN}

Recorridos de superficie realizados en la cuenca lacustre del Tamesí (2007 a 2009), permitieron la localización y muestreo de 31 nuevos sitios arqueológicos. La identificación de cerámica diagnóstica con la aplicación de una tipología desarrollada para caracterizar la función y contexto de los sitios permite ofrecer un panorama de la dinámica de poblamiento para la zona de estudio, revelando un proceso que inició en el 900 a.C., deteniéndose drásticamente hacia el 200-400 d.C., quedando despoblada la región hasta que hacia el 900 d.C. comienza a repoblarse con gente ligada a Tula y Cholula. Después del año 1000 d.C. se introdujo con vigor la población propiamente llamada huasteca.

Palabras clave: Huasteca; poblamiento, contextos; cuenca lacustre; Altamira.

\footnotetext{
${ }^{1}$ Instituto Nacional de Antropología e Historia (INAH), delegación Tamaulipas, México.
} 


\begin{abstract}
Surface surveys carried out in the Tamesí lake basin (2007 to 2009), allowed the location and sampling of 31 new archaeological sites. The identification of diagnostic ceramics with the application of a typology developed to characterize the function and context of the sites, allows to offer a panorama of the population dynamics for the study area, revealing a process that began in $900 \mathrm{BC}$, stopping drastically towards $200-400 \mathrm{AD}$, the region being depopulated until about $900 \mathrm{AD}$ begins to repopulate with people linked to Tula and Cholula. After the year 1000 AD the population proper called huasteca was introduced with vigor.
\end{abstract}

Keywords: Huasteca; Peopling; Contexts; Lacustrian; Basin; Altamira.

\title{
EL PROYECTO ASENTAMIENTOS PREHISPÁNICOS DE LA CUENCA LACUSTRE TAMESÍ-PÁNUCO
}

Entre los años 2007 al 2009 se realizaron tres temporadas de campo del proyecto Asentamientos Prehispánicos de la Cuenca Lacustre del Tamesí- Pánuco (PCL), mismo te tenía como objetivo principal el de:

...obtener un amplio corpus documental, tanto bibliográfico, fotográfico, videográfico, fonográfico, cartográfico, de material arqueológico, osteológico y genético que permita conocer, mediante su análisis integral, el modo de vida lacustre de la población asentada en la cuenca Tamesí- Pánuco, así como sus relaciones internas y externas a través del tiempo pasado y el presente (Ramírez 2006: 29).

Un objetivo demasiado ambicioso, pero factible como estudio integral y multidisciplinario de área, que se vio frustrado principalmente porque en el año 2010 la violencia criminal estalló en el noreste de México, extendiéndose a través de los municipios y ejidos en donde se realizaba la investigación, lo que me obligó a suspenderla indefinidamente. De todo lo programado, únicamente se 
pudo llevar a cabo el recorrido de superficie que reportó el hallazgo de 31 nuevos sitios arqueológicos en la zona, cuyos materiales diagnósticos, principalmente cerámicos, nos brindan una visión cronológica de la dinámica poblacional prehispánica. Adicionalmente, los datos contextuales de topoformas asociadas a los recursos hídricos ampliamente disponibles en el área de estudio, sugieren ciertas preferencias de asentamiento en determinados periodos, asociados también a determinados sistemas constructivos y la presencia de otros elementos como arquitectura, escultura, petrograbados, posibles restos de escoria de fundición de cobre, salinas y chapopoteras, que nos permiten caracterizar los sitios para inferir las preferencias espaciales de sus habitantes por periodos, así como la función que cumplían los asentamientos, ya sea habitacional, ceremonial, ritual o de suministro.

Los nuevos sitios localizados por el PCL sumados a los ya conocidos antes (Las Flores, Tancol, Isla de la Pitahaya, Nuevo Amanecer, Mata del Muerto, Chak Pet y Tierra Alta), así como los pocos agregados por salvamentos arqueológicos anteriores, no superan los 60 sitios arqueológicos; mismos que representan sólo una pequeña porción de los muchos que aún existen, especialmente hacia el norte, sur y poniente del vaso lacustre. Por lo anterior, es necesario que se continúe la localización y registro de esos sitios aún desconocidos, con el objetivo de completar y ampliar la somera visión que se presenta en este estudio, antes de que el desarrollo urbano e industrial los destruya. 


\section{La zona de estudio}

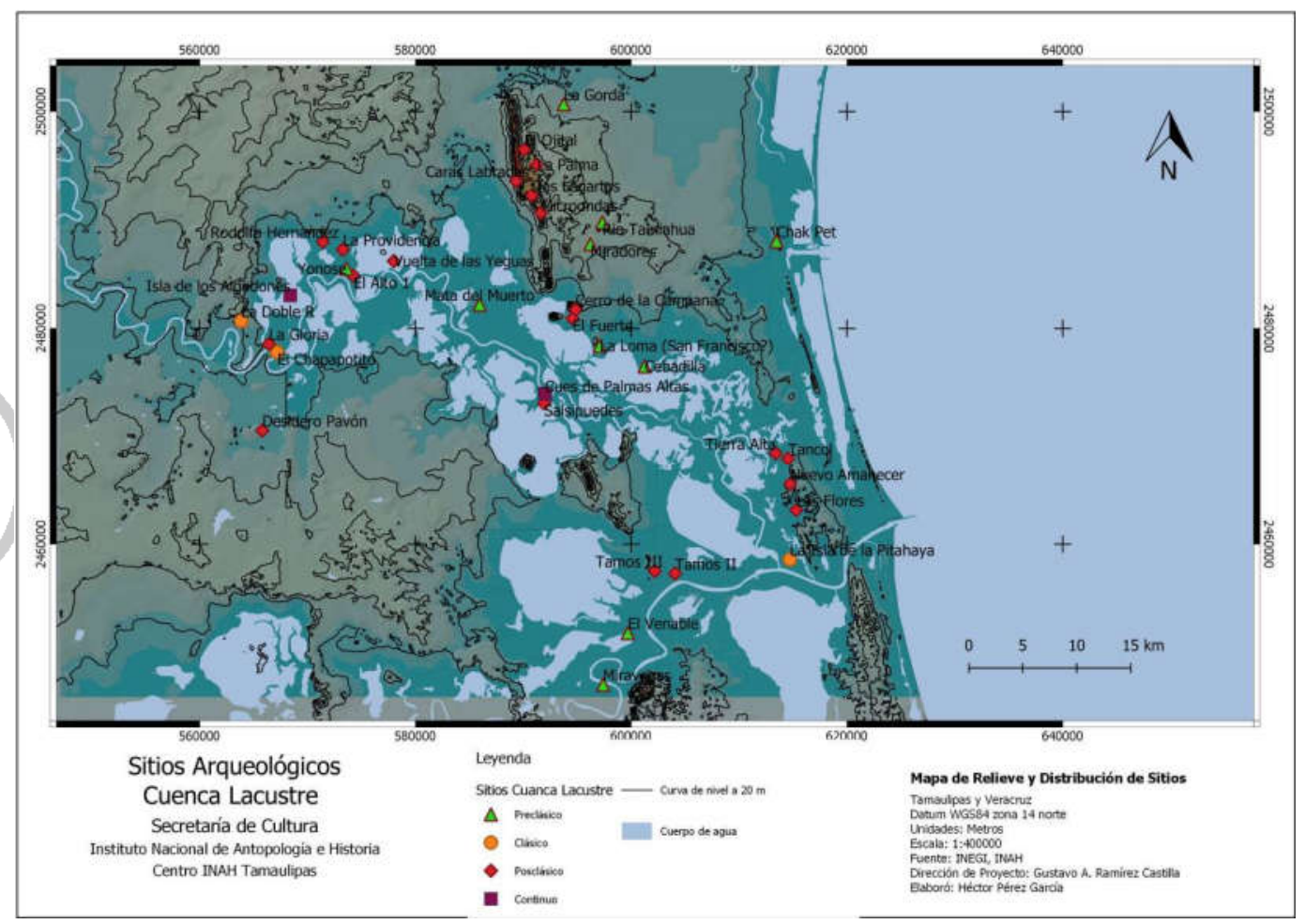

Figura 1. Área de estudio y ubicación de los asentamientos prehispánicos localizados en la cuenca lacustre del Tamesí. Elaboración propia. Diseño y creación: Héctor Pérez García, 2019.

La zona de estudio del PCL comprende un rectángulo de 60 x $55 \mathrm{Km}$ situado en el extremo sur de Tamaulipas, es decir, 3,300 km2. (Ramírez 2006: 4), que abarca parcialmente los municipios de Altamira, González, Madero y Tampico en el Estado de Tamaulipas, y los municipios de Pánuco, Pueblo Viejo y Tampico Alto en el Estado de Veracruz (Ver figura 1). Incluye como cuerpos principales los ríos 
Tamesí, Pánuco y Barberena; así como el vaso lacustre con sus diversas lagunas y las marismas situadas en la costa del Golfo de México. La mayor parte del relieve de la zona es plano con lomeríos bajos, pero destacan algunas elevaciones como la Sierra de la Palma, el Cerro del Metate, el Cerro del Lagarto, La Cruz y el Esporta, en el municipio de Altamira, y el Cerro de Andonegui en Tampico, (ídem); así como la Mata Redonda en la margen derecha del Pánuco.

El clima de la zona de estudio, de acuerdo con la clasificación climática modificada de Köppen, es subhúmedo con lluvias en verano las cuales presentan dos máximos separados por dos estaciones de secas; una larga en la mitad fría de año y una corta en la mitad de la temporada lluviosa [Aw(i') w"j] (García, 1988, Ramírez 2006: 4).

\section{HIDROGRAFÍA}

\section{Río Pánuco}

Nacido en los profundos drenajes del Valle de México, el río Pánuco hace un largo recorrido de $510 \mathrm{Km}$ (Carbajal et al. 2015: 6) para, finalmente, desembocar en el Golfo de México, en la barra de Tampico. Los últimos $15 \mathrm{Km}$ del río son navegables para buques de gran calado de hasta 20,000 toneladas. A partir del punto conocido como El Prieto, río arriba, el Pánuco es navegable para lanchas y chalanes de medio tonelaje en una distancia de $225 \mathrm{Km}$ (Ramírez 2006: 5). Como puede apreciarse esta vía fluvial es y fue una importante y rápida vía de comunicación del centro de México a la costa, hoy desaprovechada, pues el mayor 
tráfico se hace por carreteras y vías férreas. En la época prehispánica y luego durante la Colonia, jugó un papel fundamental en las comunicaciones y como eje de los asentamientos humanos debido a la prolijidad de sus recursos. Francisco de Garay (conquistador español) navegó cincuenta leguas río arriba, avistando cuarenta pueblos distribuidos en ambas márgenes del río (Toussaint, 1948).

La cuenca hidrológica del Pánuco es una de las más importantes del país, ocupa una superficie de $83,884.2 \mathrm{~km} 2$, que representa el $4.3 \%$ del territorio nacional, con una descarga anual de 16,500 millones de metros cúbicos (Carbajal et. al 2015:6).

\section{Río Tamesí}

Nace al norte de Miquihuana, Tamaulipas con el nombre de Alamar, corriendo hacia el oriente donde se junta con el Arroyo Maravillas, en Palmillas, punto donde recibe el nombre de Xigüe o Chihue. A la altura de Llera de Canales es más conocido nombre de Guayalejo y a partir de González se conoce ya como Tamesí. (Rolón et al. 2012: 8) Desde este último punto es navegable para lanchas y lanchones hasta su final, $150 \mathrm{Km}$. río abajo.

En su curso inferior se encuentra bordeado por varias lagunas, formando un delta. Para acortarlo y favorecer la navegación, en 1847 se excavó el Canal Americano, que termina a poca distancia del Moralillo. Hasta la segunda década del siglo XX, el río Tamesí corría paralelo al Pánuco, y se reunía con éste en La Isleta; pero con 
su mismo azolve, que extraían las dragas, se cegó este cauce actualmente urbanizado, confluyendo ambos ríos desde entonces en el mencionado Moralillo.

\section{Sistema lagunar}

El vaso lacustre formado por el río Tamesí corresponde a un delta joven en formación, próximo a la desembocadura del río Pánuco, flujo que corre paralelo a la margen derecha del primero, alcanzando el litoral del Golfo de México donde se descarga. El complejo lagunar se ubica mayormente dentro de la provincia fisiográfica Llanura Costera del Golfo Norte, subprovincia Llanura Costera Tamaulipeca, que abarca los municipios de Tampico, Madero y una parte de Altamira (CONAGUA 2015: 5). Sin embargo, el espejo lacustre de más de 30 mil hectáreas cuadradas de extensión (ídem), comprende un conjunto de lagunas que, como ya se dijo, se extienden por los municipios vecinos de González en Tamaulipas, así como Pánuco, Pueblo Viejo y Tampico Alto en Veracruz. Investigación Arqueológica

A finales del siglo XIX y principios del siglo XX, el desarrollo de la antropología como ciencia favoreció el acercamiento de destacados investigadores que dejarían una huella profunda en los estudios huastecos, impulsando el interés de nuevas generaciones de arqueólogos, lingüistas, antropólogos e historiadores que, ya avanzado el siglo, habrían de sembrar las nuevas bases teóricas para comprender los procesos, desarrollo y dinámica cultural de la Huasteca. 
Los primeros en incursionar el sur de la zona fueron Eduard Seler (1888) y su esposa Cecile, quienes hicieron una serie de notas y dibujos de los sitios arqueológicos y sus materiales en la segunda mitad del S. XIX. Para 1873, el ingeniero topógrafo y gobernador de Tamaulipas, don Alejandro Prieto (1975 [1873]), publicó su Historia, geografía y estadística del Estado de Tamaulipas. En ella hace un recuento de los principales sitios arqueológicos situados en el sur de la entidad, concentrando sus esfuerzos particularmente en la Sierra de la Palma y las lagunas situadas frente a Altamira. Ilustra su obra con litografías que muestran un edificio circular de piedra con escalinatas, así como varios objetos de la cultura material; no obstante, el poco realismo de los bocetos hace pensar que el Ing. Prieto deseaba mostrar que los pueblos ancestrales de Tamaulipas hacían objetos de proporciones "clásicas", y que eran por lo tanto "civilizados", punto este en el que difería de Orozco y Berra, quien había afirmado que la región había estado poblada por salvajes (Ramírez, 2006).

(Figura 2. Ruinas indígenas de la Sierra de la Palma. Alejandro Prieto. 1873).

Durante los primeros años del siglo XX llegaría a la Huasteca, como parte de un extenso viaje para reconocer las manifestaciones culturales de la Costa del Golfo, el destacado arqueólogo norteamericano Jessie Walter Fewkes (1850 - 1930). 


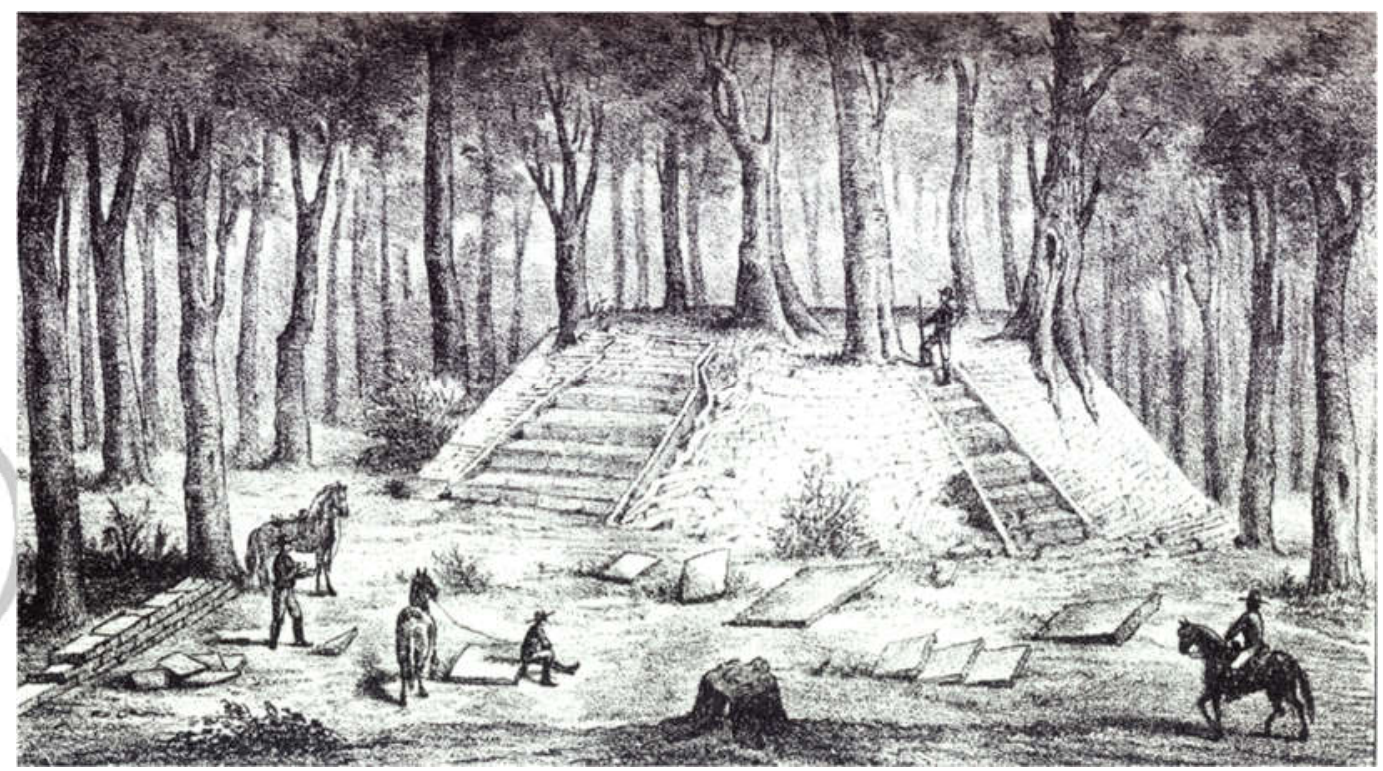

Figura 2. Ruinas indígenas de la Sierra de la Palma. Litografía de la pirámide del sitio La Palma, ostenta forma de cono truncado, recubierto de piedra tallada y con escalinatas. Todavía existe el montículo con las características descritas. Tomado de Prieto 1975 [1873].

$\mathrm{Su}$ viaje obedece a la vieja inquietud de saber si existen relaciones entre los materiales culturales de la Costa del Golfo y el área maya con los del valle del Mississippi. Entonces, con financiamiento del Instituto Smithsoniano, en el invierno de 1905 emprende su recorrido por los Estados orientales de la República Mexicana, expresamente Veracruz y Tamaulipas, publicando un par de años después su conocido reporte Certain antiquites of eastern Mexico (1907). En la primera parte, correspondiente al Estado de Veracruz, Fewkes da a conocer una 
amplia información sobre los diversos sitios que visitó en esa entidad; mientras que en la segunda parte aborda específicamente los sitios de Tamaulipas, sobresaliendo su descripción del sitio Las Flores, aunque no bajo ese nombre sino como "Rancho del Sr. Külke". El texto es de gran importancia por ser la primera vez que se escribe acerca del sitio, en una época en que todavía no había sido alterado. Más adelante trata sobre los sitios rancho San Francisco y La Palma, municipio de Altamira, de los sitios Topila y Palachó en los alrededores de la laguna Champayán que, aunque de interés, resultan ser una copia de las observaciones de Alejandro Prieto. Finaliza haciendo comentarios sobre diversos objetos que observó, entre ellos una diosa de piedra que, hasta el momento de su visita, se mantenía empotrada en el muro de una casa situada frente al Hotel Comercio (Fewkes, Op.Cit.) A su regreso en Washington, Fewkes descubrió que las bodegas smithsonianas guardaban varios objetos huastecos que pudo identificar. De sus conclusiones entresaco los siguientes puntos:

1) los montículos de tierra en el este de México son bases para templos que desde su origen fueron construidos con esa forma troncocónica no ocasionada por la caída de techos con acumulación de desechos y sedimentos encima;

2) La analogía más cercana es con los montículos del valle del Mississippi; sin embargo, la cultura de los sobrevivientes de esos antiguos constructores de montículos en ambas regiones, Mississippi y Huaxteca es bastante distinta de la de sus ancestros;

3) La región que se extiende desde los montículos más septentrionales de Tamaulipas, hasta el río Grande o Bravo, es una región con gran potencial, pero 
mientras que esa tierra incógnita no sea debidamente estudiada, poco se puede especular sobre las relaciones entre los montículos de Louisiana y los del este de México (ibídem: 284).

Pocos años después de Fewkes llegarían otros exploradores. Hacia 1923, el ingeniero alemán Frederick K.G. Muelleried, quien un año después publica Algunas observaciones sobre los “cues” en la Huasteca (1924). En 1925 a raíz de la destrucción de los montículos de Las Flores, el ingeniero Jhon Muir realiza un levantamiento topográfico del sitio, así como un estudio del sistema constructivo de los montículos que publica con el nombre de Data on the Structure of PreColumbian Huastec mounds in the Tampico region, Mexico (1926). Lamentablemente por razones inexplicables el plano topográfico que hizo de Las Flores no se publicó en esa edición. En su artículo trata de aplicar un método científico para el estudio de los "cúes", pues en aquellas épocas seguía en debate su forma, contenido y función.

Uno de sus objetivos era definir las relaciones que guardaban entre sí los sitios de Santa Fe, Las Flores y Palacho, por lo cual encarga su levantamiento topográfico al señor Cecile Drake. De Santa Fe destaca que guarda una orientación de $20^{\circ} \mathrm{E}$, que tiene "pavimentos" y aplanados de cal - arena como Las Flores. Acerca de Palacho sólo dice que las laderas de los montículos están recubiertas con lajas de arenisca fáciles de obtener en las cercanías. 
Por esas mismas fechas el historiador potosino Joaquín Meade Trápaga (1896 1971) ya se encuentra haciendo extensos recorridos de campo o hurgando viejos papeles en busca de la historia huasteca.

Valiéndose de su talento, erudición y profundo conocimiento geográfico del área, Meade llevó a cabo la inigualable proeza de recorrer la Huasteca registrando en croquis un gran número de sitios arqueológicos. Esta información ha sido la base de ulteriores trabajos científicos. Eso sin contar la recolección y documentación de centenares de piezas arqueológicas, así como la publicación de incontables estudios, artículos y libros en donde presenta los resultados de sus investigaciones. De su amplia bibliografía sólo citaré aquí algunas de sus obras más relevantes para nuestra área de estudio. En primer lugar, La Huasteca Tamaulipeca (1977 -78) obra publicada en tres tomos por la Universidad Autónoma de Tamaulipas. La Huasteca época Antigua (1942) que incluye un listado de los sitios más relevantes de la región de Tampico- Pánuco. En esa misma obra refiere dos esculturas procedentes de las Flores, una diosa de la fertilidad y otra de un personaje sedente de estilo mexicano en cuya espalda ostenta la fecha hun coy (uno conejo) (vid Ramírez 2000).

En la década de los cuarenta llegaría la hora de los estudios científicos marcada por las excavaciones del arqueólogo norteamericano Gordon F. Ekholm del Museo Americano de Historia Natural, quien con financiamiento del Andean Institute Research, emprende un ambicioso proyecto de investigación bajo la 
Dirección del arqueólogo George C. Vaillant, quien escogió el noreste de México como un campo promisorio para la investigación arqueológica (Ekholm, 1944). Entre 1941 y 1942 Ekholm desarrolla sus investigaciones en la región comprendida entre Tampico y Pánuco, explorando diversos sitios entre los que figuran Pavón, El Prisco, Buenavista, Tancol, Chila y Las Flores. Particularmente trascendentes son sus excavaciones en el sitio Pavón, municipio de Pánuco, Ver., en donde obtiene una secuencia estratigráfica muy completa que le permite establecer las primeras fases del desarrollo cultural de la Huasteca, así como la tipología cerámica que los caracteriza. A pesar de haber sido esta una propuesta provisional, se ha mantenido vigente durante casi ocho décadas, convirtiéndose en la columna vertebral de la arqueología huasteca. Los resultados de este hito de la investigación arqueológica se publican bajo el título Excavations at Tampico and Panuco in the Huasteca, Mexico (1944).

Después de Ekholm, con pocos años de diferencia, Richard Stockton MacNeish incursiona también en la región, al realizar en Panuco, Ver., excavaciones que le permitan establecer, por una parte, correlaciones entre la cerámica encontrada por él en la Sierra de Tamaulipas con la cerámica clasificada por Ekholm y por otra, encontrar en la Huasteca un estrato precerámico comparable con la fase Diablo de la sierra y la Costa del Golfo. En conclusión, encuentra que "no existe en la Huasteca nada comparable a los cinco periodos precerámicos del Cañón del Diablo" (MacNeish 1954:172), y que dichos complejos preceden por mucho a cualquier periodo cerámico de la Huasteca, como lo indica la fecha 4,445 años 
a.p. obtenida por él en la cueva de La Perra (Idem). También establece que no hay ninguna relación entre los elementos de ambas regiones hasta las fases Laguna y La Salta, es decir, hasta los años 650 a.C. al 500 d.C. No obstante, como recompensa, a partir de sus excavaciones VC1 y VC2 en Pánuco logra establecer tres fases anteriores a la secuencia de Ekholm: Pavón, Ponce y Aguilar. Estas conformaron durante décadas el cuadro completo del desarrollo cultural Huasteca. Sus resultados se publicaron en el informe An early archaeological site near Panuco, Vera Cruz, (1954).

Otra conclusión de suma importancia a la que llega MacNeish al comparar los complejos cerámicos que encontró en Pánuco con los del sur de Veracruz es que los hablantes mayas (representados por la cerámica huasteca) ocupaban el norte de Veracruz, mientras que hablantes de nahua (representados por un complejo de cerámica intrusiva llamado Soncuautla, y relacionado con el centro de México) habitaban en el sur, en la región de Tres Zapotes, Veracruz. De lo anterior infiere MacNeish que la cerámica nahua representa el momento en que la población maya es dividida debido a una invasión de hablantes de náhuatl a la costa (Ídem: 625); acontecimiento que ubica para el periodo Clásico; hipótesis que aún debe corroborarse.

Entre 1978 y 1982, Beatriz Leonor Merino Carrión y Ángel García Cook, exploran un área de 9,500km2, que abarcan porciones de las Huastecas Potosina, Veracruzana y Tamaulipeca. El Proyecto Arqueológico Huaxteca (P.A.H), llevó a 
cabo un reconocimiento sistemático de este territorio comprendido entre los límites septentrionales de la Huasteca y las Llanuras norteñas, caracterizado por ser una planicie con algunos lomeríos de poca elevación cuyas alturas no rebasan los 10 a 200 metros sobre el nivel del mar (Merino y García, 1987: 31). Como resultado se localizaron 525 asentamientos humanos prehispánico, de los cuales 483 pertenece a grupos sedentarios y 42 a de grupos nómadas, estos últimos situados principalmente en el área de embalse de la Presa San Lorenzo, en Xicoténcatl, Tamaulipas (ídem, 32-33).

El estudio de los materiales, tanto de superficie como de excavación permitió al matrimonio García Merino proponer una nueva secuencia del desarrollo cultural de la región, sustentada en las tipologías cerámica de Ekholm y MacNeish, con mejoras, adiciones y correcciones, pero amarrada a datos duros como los fechamientos por radiocarbono, el patrón de asentamiento y la presencia de otros elementos y materiales asociados como los entierros humanos, figurillas, herramientas etc. Esta secuencia cultural ha revolucionado por completo la visión plasmada por Ekholm, ya que no se reduce a una serie de cambios estilísticos en la cerámica comparables a otras regiones de Mesoamérica, sino que plantea de manera dinámica pero especialmente cualitativa los cambios, qué relación tienen con la climatología y la demografía, así como los contactos a larga distancia con sociedades mesoamericanas e incluso del Sureste de los Estados Unidos, a través del intercambio de productos (figura 3). 


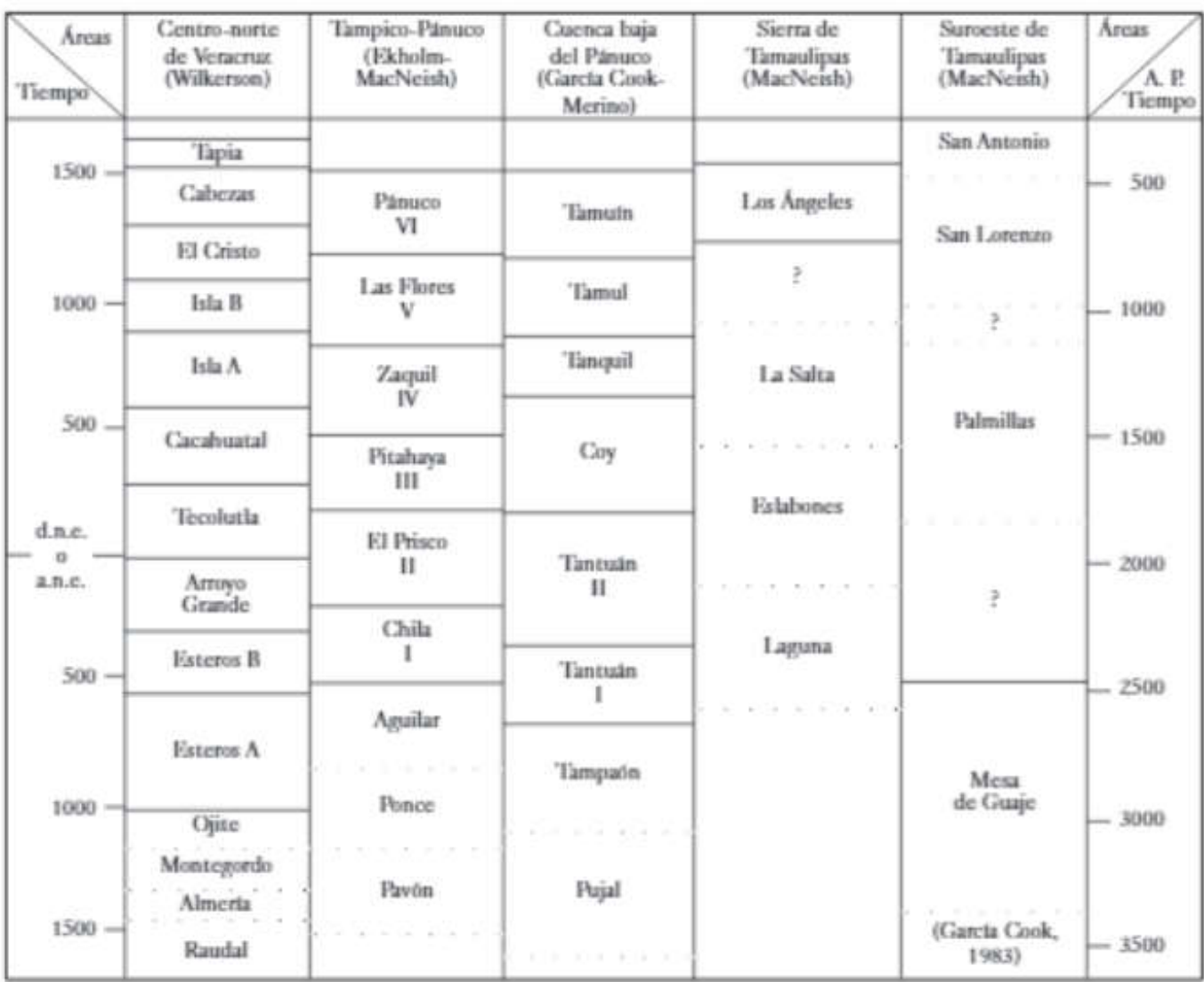

Figura 3. Secuencia cultural de la cuenca baja del Pánuco. Tomado de García Cook y Merino Carrión 2004.

Una investigación no directamente relacionada con nuestra zona de estudio, pero importante por sus repercusiones para comprender los patrones de asentamiento en la Huasteca es la tesis profesional de Gerardo Gutiérrez (1996) derivada del proyecto Arqueología de la Cuenca de la Laguna de Tamiahua, en el que registro de 77 sitios localizados entre la Sierra de Otontepec y la Laguna de Tamiahua, en 
el estado de Veracruz. Igualmente incluye 26 sitios más de Veracruz, Tamaulipas, San Luís Potosí e Hidalgo (Gutiérrez, Op. Cit.: 2). El estudio de los materiales e información recuperada en dicho proyecto ha permitido proponer para el sur de la Huasteca, la existencia de un patrón de asentamiento condicionado por factores naturales como la topografía y el acceso a las fuentes de agua, como por el surgimiento de centros rectores, representados por sitios con más de 21 edificios, que dominaban a otros de menor tamaño representado por sitios de siete rangos inferiores. Dicho patrón coincide con la información proporcionada por las fuentes, acerca de la existencia de tres niveles de agregación de la población; el pueblo o Bichou, como centro rector, donde vivían las elites gobernantes, clases privilegiadas y servidumbre; los barrios o rancherías situadas en torno al Bichou, llamadas Quamchalab, donde vivía la población agrícola en unidades habitacionales llamadas Quima (ibídem: 271).

Otros proyectos que han aportado información valiosa sobre los asentamientos prehispánicos de nuestra área de estudio han surgido de la necesidad de salvamentos arqueológicos, como el Salvamento Arqueológico en el Gasoducto Cactus-Reynosa que, en el tramo correspondiente a Tamaulipas, localizó un sitio en el pueblo de Aquiles Serdán, Mpio. de Altamira, en donde se recuperaron más de 50 enterramientos prehispánicos (Ramírez 2006: 12). A partir del establecimiento del Centro INAH en el Estado de Tamaulipas en 1995, se inició una etapa de inspecciones, rescates y exploraciones sistemáticas. Entre estos tenemos el rescate arqueológico de Tierra Alta en Tampico, a cargo Gustavo A. 
Ramírez, que proporcionó importantes datos sobre el asentamiento del postclásico reportado por Meade en los cuarenta (Ramirez 2000), A finales del año 2000 se realizó el Salvamento Arqueológico en la Línea de Trasmisión Eléctrica Puerto Altamira - Champayán, que comprendió $33 \mathrm{Km}$ de recorrido (Reza 2010: 7). En 2001se continuó con el salvamento arqueológico en la Línea de Trasmisión Eléctrica Champayán -Anáhuac- Potencia con un recorrido de $96 \mathrm{Km}$ que abarcó el sur de Tamaulipas y una fracción de Veracruz, hasta Tamuín, S.L.P. (ídem). Entre 2004 y 2005, Pamela Reza Martínez realizó un salvamento arqueológico de $170 \mathrm{Km}$ lineales entre el sur de Tamaulipas a Tamazunchale, S.L.P., que arrojó la localización de 66 sitios arqueológicos (ibídem: 8), que derivó en la tesis profesional Asentamientos prehispánicos en la Huaxteca Septentrional. Un estudio a partir de Salvamentos Arqueológicos en Líneas de Trasmisión Eléctrica (Reza 2010).

A finales del año 2006 dio inicio al Salvamento Arqueológico Puerto Altamira (Ramírez y Marchegay 2007, 2008 y 2010, Ramírez et al. 2007, 2008), que con diversas temporadas se ha prolongado hasta el año 2019. El área de este salvamento corresponde a las 10 mil hectáreas del Puerto Industrial de Altamira, donde se han localizado trece sitios arqueológicos, de los cuales se han excavado extensivamente sólo dos. Uno de ellos, el más relevante, es Chak Pet, que reporta la segunda mayor antigüedad en la Huasteca, entre los años 900 a.C. - 200 d.C. (Ramirez 2016: 71-82), siendo el primero Altamirano, en Pánuco, Veracruz, cuya antigüedad se remonta hasta el 1700 a.C. (Castañeda 1989 y 1992). Un primer 
aporte de dicho proyecto al conocimiento de la cerámica preclásica ha sido la tesis: Cerámica Arqueológica de Altamira, Tamaulipas. El Formativo tardío en un sitio costero huasteco, de Héctor Pérez García (2012), la primera que aborda el análisis tipo-variedad de la cerámica formativa de la Huasteca. Otras tesis derivadas de dicho proyecto son: La Lítica de la Planicie Costera de Tamaulipas, de Irán Roxana Domínguez Rodríguez (2009), Mismos Espacios, Diferentes Paisajes. La API-Altamira: Sitios Arqueológicos, Históricos y El Puerto de Gran Calado, de Tonantzin B. Silva Cárdenas (2013), La Actividad Física de los Antiguos Pobladores de Chac Pet, Altamira, Tamaulipas, de Argelia Francisco Martínez (2016), Entre manos y pies. Prácticas funerarias en el norte de la Huasteca, formativo terminal, de Víctor Hugo Valdovinos Pérez (2018).

\section{Resultados del PCL}

La Tabla 1 nos muestra los sitios localizados durante los recorridos de superficie, así como los ya conocidos. También concentra los principales datos que se pueden recabar a partir de los tipos diagnósticos de cerámica y los contextos donde se ubican. En la figura 1 se muestra el mapa de la región de estudio, que permite visualizar la ubicación y distribución de los sitios en la cuenca lacustre. El mapa muestra los sitios cronológicamente, con signos que los ubican por periodos en el preclásico, clásico y postclásico, así como aquellos que tuvieron una continuidad de ocupación en los tres periodos. Los sitios con los numerales 1,2,3,4 son sitios arqueológicos ya explorados anteriormente por Ekholm (1944.), el número 15, El Venable, fue explorado durante el Salvamento L.T. Tamos - Pánuco (Ramírez 
1996) y el número 38 corresponde al sitio 1 de 13 localizados dentro del recinto portuario de Altamira (Ramírez y Marchegay 2007).

Para la localización de los sitios en el PCL se recurrió en primer lugar a la consulta de publicaciones, las ya mencionadas de Prieto (1873), Fewkes (1907), Ekholm (1944), MacNeish (1954). De los sitios reportados por Prieto, el sitio número 8, La Palma, y 26, La Loma (Rancho San Francisco), cuya ubicación se desconocía, fueron redescubiertos en la temporada 2008, gracias a sus indicaciones. De Fewkes se retoma la descripción y plano del sitio Las Flores, reportado entonces como Rancho del Sr. Külke. De Ekholm se retomó la ubicación y descripciones de Tancol, Las Flores y la Isla de la Pitahaya. No obstante, otros sitios recorridos por él, en los cuales recuperó importantes muestras de cerámica, como Chila, El Prisco y Zaquil, fueron imposibles de relocalizar, en parte debido a que no dejó un plano con ubicaciones precisas, ni indicaciones para llegar.

El sitio Chila es de sumo interés, pues según Bernal Díaz del Castillo fue en esa aldea donde encontraron los cueros de los soldados de Francisco de Garay sacrificados por los Huastecos (Ramírez et al. 2008:53) lo que motivó la destrucción de la aldea y la matanza de cuarenta caciques por parte de los españoles (ídem). Es posible que el sitio reportado como Chila por Ekholm (1944: 420-421) corresponda con el denominado El Venable, situado casi en la misma ubicación, y excavado en 1996 (Ramírez 1996); pero cuyos materiales 
corresponden sin duda al periodo preclásico, como el mismo Ekholm lo señala (ídem); por lo que sin duda no corresponde al lugar mencionado por los españoles y que es necesario continuar buscando.

\begin{tabular}{|c|c|c|c|c|c|}
\hline \multicolumn{6}{|c|}{ ASENTAMIENTOS PREHISPANICOS DE LA CUENCA LACUSTRE TAMESÍ - PANUCO } \\
\hline \multicolumn{6}{|c|}{ SITIOS REGISTRADOS } \\
\hline NUMERO & NOMBRE & MUNICIPIO & ESTADO & TIPO & PERIODO \\
\hline Columna +1 & Columna2 & Columna ${ }^{-}$ & Columna4 & Columna5 & Columna6 \\
\hline 1 & LAS FLORES & TAMPICO & TAMAULIPAS & COLINA/LAGUNA & POSTCLÁSICO \\
\hline 2 & TANCOL & TAMPICO & TAMAULIPAS & COLINA/LAGUNA & POSTCLÁSICO \\
\hline 3 & ISLA DE LA PITAHAYA & TAMPICO & TAMAULIPAS & ISLA/LAGUNA & CONTINUO \\
\hline 4 & TIERRA ALTA & TAMPICO & TAMAULIPAS & TIERRA ALTA/LAGUNA & POSTCLÁSICO \\
\hline 5 & MATA DEL MUERTO & ALTAMIRA & TAMAULIPAS & ISLA/LAGUNA & PRECLÁSICO \\
\hline 6 & RIO TAMIAHUA & ALTAMIRA & TAMAULIPAS & LOMA/LLANURA & PRECLÁSICO \\
\hline 7 & DOS LAGARTOS & ALTAMIRA & TAMAULIPAS & SIERRA/VENERO & POSTCLÁSICO \\
\hline 8 & LA PALMA & ALTAMIRA & TAMAULIPAS & SIERRA & POSTCLÁSICO \\
\hline 9 & CUES DE PALMAS ALTAS & ALTAMIRA & TAMAULIPAS & TIERRA ALTA/RIO & CONTINUO \\
\hline 10 & CERRO DE LA CAMPANA & ALTAMIRA & TAMAULIPAS & CERRO/LAGUNA & POSTCLÁSICO \\
\hline 11 & EL ALTO 1 & GONZALEZ & TAMAULIPAS & LOMA/LLANURA & POSTCLÁSICO \\
\hline 12 & LA PROVIDENCIA & GONZALEZ & TAMAULIPAS & TIERRA ALTA/LAGUNA & POSTCLÁSICO \\
\hline 13 & VUELTA DE LAS YEGUAS & GONZALEZ & TAMAULIPAS & TIERRA ALTA/RIO & POSTCLÁSICO \\
\hline 14 & YONOSE & GONZALEZ & TAMAULIPAS & LOMA/LLANURA & NO IDENTIFICADO \\
\hline 15 & EL VENABLE & PANUCO & VERACRUZ & TIERRA ALTA/LAGUNA & PRECLÁSICO \\
\hline 16 & MIRAVEGAS & PANUCO & VERACRUZ & TIERRA ALTA/RIO & PRECLÁSICO \\
\hline 17 & TAMOSI & PANUCO & VERACRUZ & TIERRA ALTA/RIO & POSTCLÁSICO \\
\hline 18 & TAMOS II & PANUCO & VERACRUZ & TIERRA ALTA/RIO & PRECLÁSICO \\
\hline 19 & TAMOS III & PANUCO & VERACRUZ & TIERRA ALTA/RIO & POSTCLÁSICO \\
\hline 20 & EL CHAPAPOTITO & GONZALEZ & TAMAULIPAS & LOMA/LAGUNA & CLASICO \\
\hline 21 & LA DOBLE R & GONZALEZ & TAMAULIPAS & LOMA/LLANURA & CLASICO \\
\hline 22 & LA GLORIA & GONZALEZ & TAMAULIPAS & TIERRA ALTA/RIO & POSTCLÁSICO \\
\hline 23 & RODOLFO HERNANDEZ & GONZALEZ & TAMAULIPAS & LOMA/LAGUNA & POSTCLÁSICO \\
\hline 24 & ISLA DE LOS ALGODONES & GONZALEZ & TAMAULIPAS & ISLA/LAGUNA & PRECLÁSICO \\
\hline 25 & LA CEBADILLA (3 MAYO) & ALTAMIRA & TAMAULIPAS & TIERRA ALTA/LAGUNA & CLASICO \\
\hline 26 & LA LOMA (SAN FRANCISCO) & ALTAMIRA & TAMAULIPAS & LOMA/LAGUNA & PRECLÁSICO \\
\hline 27 & EL FUERTE & ALTAMIRA & TAMAULIPAS & LOMA/LAGUNA & POSTCLÁSICO \\
\hline 28 & SALSIPUEDES & PANUCO & VERACRUZ & LOMA/LAGUNA & CONTINUO \\
\hline 29 & LA ANGOSTURA & PANUCO & VERACRUZ & TIERRA ALTA/RIO & NO IDENTIFICADO \\
\hline 30 & CERRO DE LA TORTUGA & PANUCO & VERACRUZ & ISLA/LAGUNA & NO IDENTIFICADO \\
\hline 31 & EL CANTARITO & PANUCO & VERACRUZ & TIERRA ALTA/RIO & NO IDENTIFICADO \\
\hline 32 & EL CORCOVADO & PANUCO & VERACRUZ & TIERRA ALTA/RIO & POSTCLÁSICO \\
\hline 33 & MAYORAZGO ALTO & PANUCO & VERACRUZ & TIERRA ALTA/RIO & NO IDENTIFICADO \\
\hline 34 & LA HERRADURA & PANUCO & VERACRUZ & TIERRA ALTA/RIO & NO IDENTIFICADO \\
\hline 35 & MATA DEL ABRA & PANUCO & VERACRUZ & TIERRA ALTA/RIO & NO IDENTIFICADO \\
\hline 36 & DESIDERIO PAVON & ALTAMIRA & TAMAULIPAS & TIERRA ALTA/RIO & NO IDENTIFICADO \\
\hline 37 & CHUNCA & PANUCO & VERACRUZ & TIERRA ALTA/RIO & POSTCLÁSICO \\
\hline 38 & LOMAS DE REAL (CHAK PET) & ALTAMIRA & TAMAULIPAS & LOMA/MARISMA & PRECLÁSICO \\
\hline
\end{tabular}

Tabla 1. Sitios localizados durante las temporadas 2007-2009 del Proyecto Asentamientos Prehispánicos de la Cuenca Lacustre del Tamesí. Elaboración propia. 
En segundo lugar, se recurrió a la exploración del área mediante el uso del programa Google Earth $\odot$. A través de la observación de diferenciaciones de vegetación, de volúmenes y de topoformas como lomas, islas, cerros, se intentó localizar sitios potenciales, que fueron trasladados a las cartas topográficas de INEGI 1:50 000, mismas que fueron la guía definitiva para acceder a los diversos sitios. Sin embargo, la baja resolución de la fotografía satelital para la zona hizo muy imprecisa nuestras observaciones, por lo que no se puede decir que haya sido una estrategia exitosa para localizar sitios. Lo que definitivamente fue la mejor técnica para ubicarlos fue el recorrido físico, con una gran dosis de ayuda de informantes, algunos de los cuales nos condujeron de la mano hasta los sitios mismos.

Una vez localizados los sitios se procedió a la inversa, tratando de ubicarlos en el mapa de Google Earth (C), y en algunas ocasiones fue posible observar someramente las elevaciones de lomas o montículos. Aunque generalmente se trató de hacer un croquis a mano alzada con ayuda de brújula y cinta, la necesidad de desbrozar el área a veces requería de un tiempo precioso del que no se disponía, por lo que los croquis fueron someros; pero concentramos esfuerzos en recolectar materiales diagnósticos en forma aleatoria, pues la ubicación cronológica era una prioridad, ya que se tenía en mente que en otro momento se podría regresar a realizar los levantamientos topográficos detallados. 
Para la ubicación cronológica de los sitios se retomó la secuencia cultural para la cuenca baja del Pánuco propuesta por Ángel García Cook y Leonor Merino (2004) (ver figura 3), que como se dijo es más completa que las propuestas por Ekholm (1944) y MacNeish (1954), remontándose del 1521 hasta el 1800 a.C., en trece fases datadas mediante radiocarbono.

\section{Cerámica diagnóstica}

Aunque durante los recorridos fue posible recolectar diversos tipos de material como lítica, concha o caracol, la cerámica fue la preferida por sus cualidades para establecer una cronología relativa de los sitios, enfocándonos en tiestos que presentaban de manera reconocible las formas, o el acabado y la decoración; elementos característicos de los tipos cerámicos establecidos por Ekholm (óp. cit.) y las diversas tipologías derivadas de él hasta entonces para la Huasteca (Vid MacNeish 1954,Castañeda 1989, 1992, García Samper 1982, Zaragoza 2005, Espinoza 2008, Pérez 2010). Aunque las vajillas y tipos característicos para cada uno de los tres periodos mesoamericanos -Preclásico, Clásico y Postclásico-, son abundantes, aquí sólo me referiré a los más diagnósticos y característicos de cada periodo, tomando como base la tipología establecida por Ekholm (1944) y complementada por Héctor Pérez García (2010) para Chak Pet, el sitio más explorado del área. Esta última tipología -cómo ya se comentó-, sigue el método tipo - variedad, y retoma, corrige y afina las otras tipologías propuestas antes, adicionando las variantes estilísticas, agrupándolas en vajillas y caracteriza con mayor detalle las pastas y aspectos tecnológicos no contemplados antes. El 
siguiente cuadro señala los tipos cerámicos diagnósticos de cada periodo y fase de la secuencia cultural para la cuenca baja del Pánuco (figura 4.).

\begin{tabular}{|c|c|}
\hline Fase & Tipos representativos \\
\hline Chajil (1700-1400 a.n.e) & $\begin{array}{l}\text { Jabalines Gris, Granular, Rojo hematita y café esgrafiado. Y progreso } \\
\text { metálico hacia el final (Merino y Garcia, 2002:56-61) }\end{array}$ \\
\hline Pujal (1400-1150 a.n.e) & $\begin{array}{l}\text { Progreso metálico, Altamirano naranja y Altamirano blanco y negro } \\
(2002: 70-71)\end{array}$ \\
\hline \multicolumn{2}{|l|}{ Chacas (1150-900 a.n.e) } \\
\hline Tampaón (900-650 a.n.e) & Ponce negro, Aguliar Gris, Aguilar rojo y Chila blanco \\
\hline $\begin{array}{l}\text { Tantuán I }(650-350 \text { a.ne) } \\
\text { (Complejo cerámico Tancol de } \\
\text { Pérez García) }\end{array}$ & $\begin{array}{l}\text { Prisco Negro y Café paredes delgadas (Merino y Garcia, 1989:197). } \\
\text { Heavy plain alisado-pulido, variedad con aplicación de arcilla o } \\
\text { borbotina. Prisco Acanalado, variante 1. Prisco bicromo rojo y naranja. } \\
\text { Prisco inciso, variedad } 4 \text { (Pérez, 2012) }\end{array}$ \\
\hline $\begin{array}{l}\text { Tantuán II (350-100 a.n.e) } \\
\text { (Complejo Cerámico El Prisco } \\
\text { de Pérez García) }\end{array}$ & $\begin{array}{l}\text { Prisco Negro, Café paredes delgadas y Pánuco Gris (Merino y García, } \\
\text { 1989:198). Prisco Inciso, Prisco Pintado, Prisco decorado al fresco, } \\
\text { Pánuco gris, entre otros (2012:161) }\end{array}$ \\
\hline $\begin{array}{l}\text { Tantuán III (100 a.n.e a } 200 \\
\text { d.n.e) (Complejo Cerámico } \\
\text { Altamira de Pérez García) }\end{array}$ & $\begin{array}{l}\text { Muchos tipos presentes en la fase anterior continúan, sin embargo las } \\
\text { cerámicas de pastas finas se introducen y tienen continuidad hasta el } \\
\text { posclásico }(2012: 159)\end{array}$ \\
\hline Coy (200-650 d.n.e) & $\begin{array}{l}\text { La cerámica caracteristica es la de pasta fina; Pánuco pasta fina con } \\
\text { engobe rojo o blanco y se introducen en este tiempo el tipo Zaquil Rojo } \\
\text { y Zaquil Negro (Merino y Garcia, 1989:199) }\end{array}$ \\
\hline Tanquil (650-900 d.n.e) & Pastas finas, Zaquil Negro y Rojo (1989:200) \\
\hline Tamul (900-1200 d.n.e) & Tipo Las Flores negro sobre blanco, Tancol Policrono (1989:201) \\
\hline Tamuín (1200-1550 dn.e) & Negro sobre blanco, Tancol policromo (1989:202) \\
\hline
\end{tabular}

Figura 4. Tipos cerámicos asociados a cada fase. Tomado de Silva Cárdenas 2013.

\section{PERIODO PRECLÁSICO}

\section{Fases Tantuán I (650-350 a.n.e.) y Tantuán II (350 -100 a.n.e)}

\section{Vajilla Prisco}

De acuerdo con Ekholm (1944: 345) está conformada por un conjunto de cerámicas que tienen en común una pasta granular, con apariencia de migajón, quebradiza. Su coloración varía del negro al rojizo. Las vasijas fueron recubiertas 
por un engobe y pulidas en la mayor parte de su superficie, excepto en el fondo exterior. Algunas veces también el fondo interior carece de engobe, en particular el círculo central inciso como molcajete. El color del engobe varía de negro a café, pasando por el rojo, y su superficie está bien pulida y bruñida, presentando a veces pequeñas craqueladuras La vajilla Prisco es la más abundante de todas y presenta diversas variantes (figura 5), según lo indica Pérez García (2010) que incluye los tipos Prisco acanalado, con sus tres variantes (ídem: 87- 94); el tipo Prisco Bicromo Rojo y Naranja (ibídem: 95-96), tipo Prisco al Fresco (Pérez 2010: 97-100, Ekholm 1944: 346), Prisco negro (Pérez 2010: 102, Ekholm 1944: 345), Prisco inciso con cuatro variantes (Pérez 2010: 113), Prisco pintado (ibídem: 124-127), Prisco Rojo con tres variantes (ibídem: 128- 132), tipo Prisco corrugado (ibídem: 133-135).

Las cerámicas Prisco tienen una amplia distribución en los sitios de la cuenca lacustre, indicando que fue durante esta fase que se dio el auge del poblamiento de la zona La vajilla Prisco presenta además estrechas similitudes con cerámicas parecidas en pasta, forma y acabado del centro de Veracruz, como las cerámicas Acanalada, Negra y Café o Bayo de El Trapiche y Chalahuite, reportadas por García Payón (1966: 35-109), y que guardan similitudes y diferencias con otras de más al sur como Cerro de Las Mesas, La Venta e incluso Tlatilco (ibídem: 105). Cerámicas muy similares a la Prisco pueden observarse en Kaminaljuyú, y Uaxactún, de las fases Mammon y Chicanel (Ekholm 1944: 503 y 505, MacNeish 1954, Ramírez 2008). 


\section{Vajilla Pánuco Gris}

Asociada a la cerámica Prisco, generalmente aparece la llamada por Ekholm (Óp. cit.) Pánuco gris, la cual se caracteriza por tener una pasta granular, fina y muy dura, debido a su excelente cocimiento. Su color dominante es el gris claro, aunque a veces tiende ligeramente al café, con la superficie externa bien pulida, carece de engobe o pintura (ibídem: 346 ). Se ha considerado la posibilidad de separar la vajilla en tres tipos, Pánuco al fresco, Pánuco acanalado, y Pánuco gris, pero debido a la escaza presencia de los dos primeros, se ha optado por mantenerlos en un solo tipo (Pérez 2017: 82). La mayor parte de las vasijas son lisas y carentes de decoración, pero cuando la tienen es sencilla, en los molcajetes son incisiones onduladas en el fondo, o aplicaciones en pastillaje (ibídem: 83) antropomorfas y zoomorfas (figura 6). Por su color y forma guarda cierta semejanza con la cerámica gris de Monte Albán de los periodos tempranos, relacionada también con el tipo Altamirano Pánuco Gris, que Espinoza (2008) sugiere antecede al Pánuco gris y que es un marcador de un hipotético corredor cultural entre la cuenca de Pánuco y Chiapas a lo largo de la Costa del Golfo (Pérez 2010: 83), lo que nuevamente nos remite a viejas relaciones con la zona maya. 


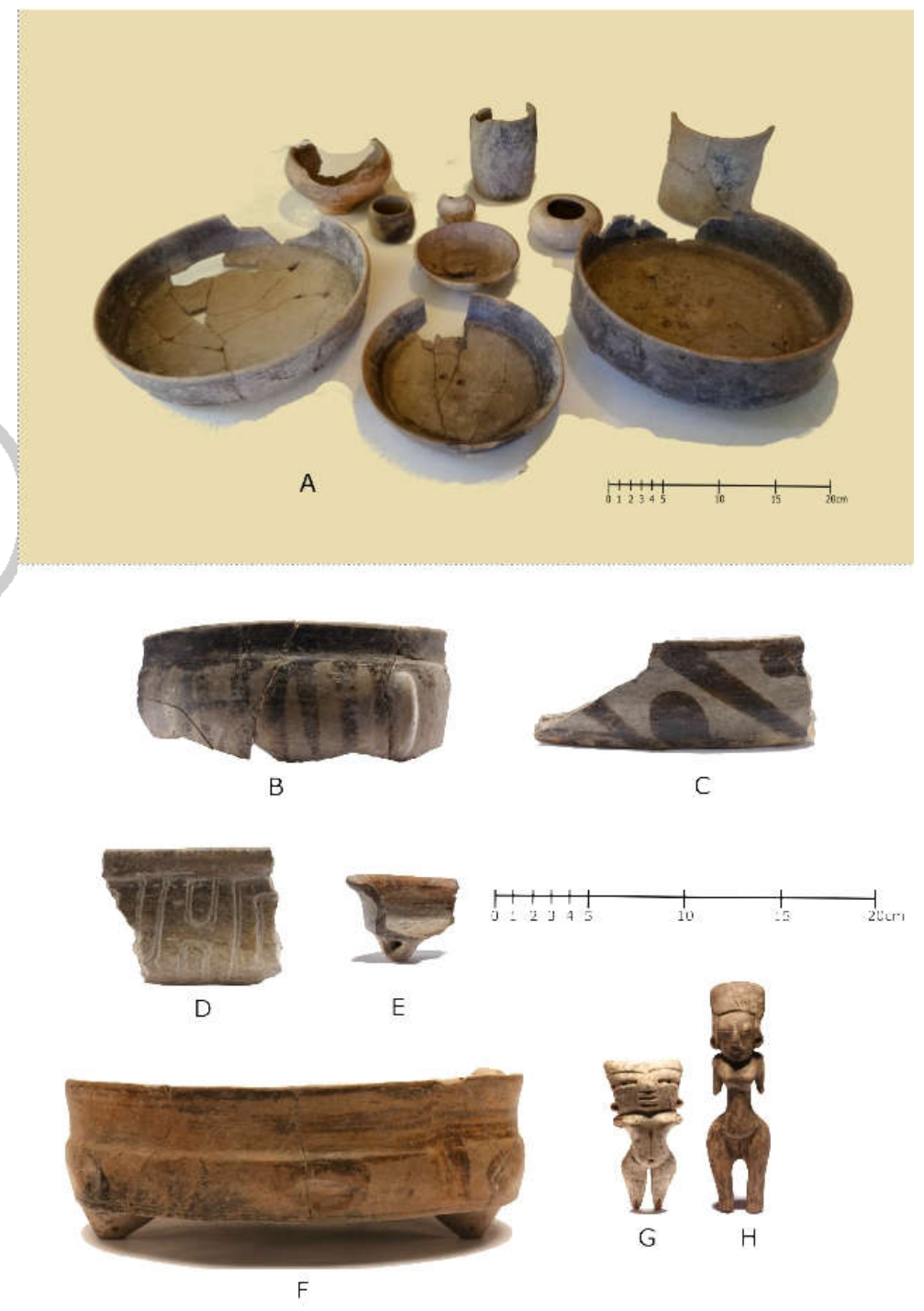

Figura 5. Vajilla Prisco y algunas de sus variantes. A) Diferentes formas de vasijas. $\mathrm{B}, \mathrm{C}$ y F) Prisco pintado. D) Prisco acanalado. E) Prisco negro, miniatura. G) Figurilla Ojos rectangulares y $\mathrm{H}$ ) Ojos bulbosos, entre otras asociadas a la vajilla Prisco. Todas son procedentes del sitio Chak Pet, Altamira. Elaboración Propia, con fotografía de Luis Martín Martínez (2014) y Gustavo A. Ramírez. 

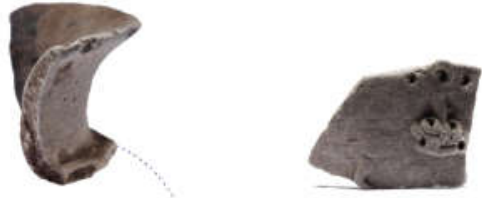

B
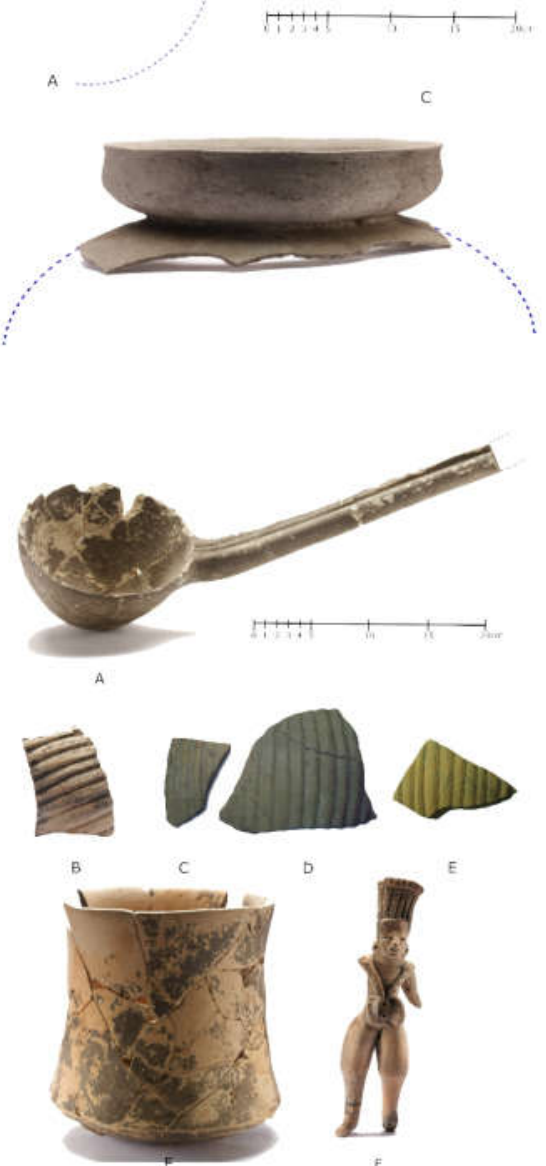

Figura 6. Tipo Pánuco Gris. A) Olla con cuello invertido. B) Borde de cuenco con aplicaciones. C) Cuello de olla con forma de cajete, una forma extremadamente rara. Todas las piezas proceden de Chak Pet, Altamira. Elaboración Propia, con fotografía de Luis Martín Martínez (2014).

Figura 7. Vajilla Pánuco Pasta Fina. A) Cucharon, un elemento generalmente asociado a esta vajilla en diversas formas y tamaños procede de Chak Pet. B-E) Cerámica del tipo corrugado, procede del sitio Chapapotito, Altamira. E) Vasija procedente de Chak Pet, Altamira. F) Figurilla tipo Pánuco C, asociada a esta vajilla, procede del Entierro 98 de Chak Pet. Elaboración Propia, con fotografía de Luis Martín Martínez (2014) y Gustavo A. Ramírez. 


\section{Periodo Clásico}

\section{Fase Tantuán III (100 a.n.e. - 200 d.n.e)}

\section{Vajilla Pánuco Pasta fina}

Gordon F. Ekholm (1944: 349) define la cerámica de este tipo como de una pasta de grano muy fino, con poco o nulo desgrasante, muy bien cocida, dura y quebradiza. Su color es café rojizo claro, más cafetoso en el centro que en la superficie. En general carece de engobe, pero está bien pulida, siendo cerosa al tacto y cuando está erosionada es polvosa (Pérez 2010: 139). Existe al menos una variante con un engobe blanco cremoso, denominada Pánuco Pasta Fina con Baño Blanco y otra con o sin baño blanco pero que es corrugada (Ekhom 1944: 349, Pérez 2010: 140). En ambos casos se presentan las mismas formas. La corrugada en particular presenta una serie de gajos verticales que parecen cortados con navaja y pulidos, aunque hay una variante con canales en sentido horizontal (Ekholm: 349-350) (figura 7).

Esta vajilla no ha sido relacionada con tipos foráneos, ni tiene antecedentes en la región; sin embargo, en mi opinión la tecnología de manufactura y la pasta fina sin engobe puede ser una imitación de la cerámica Anaranjado Delgado de Teotihuacán, que estaba de moda durante la fase Tlamiminolpa (Rattray 1979:5758). La vajilla Pánuco Pasta Fina viene acompañada de un nuevo tipo de figurillas que rompe estilística y estéticamente con la tradición anterior, ligada a la vajilla Prisco (ver figura 7F), lo cual parece indicio del arribo de una población externa, posiblemente de origen nahua, con ligas en el altiplano central (Ramírez 2008). 


\section{Periodo Postclásico}

\section{Fase Tamul (900-1200 d.n.e)}

\section{Cerámica Las Flores}

Presenta un conjunto de diferentes tipos cerámicos con características peculiares, que sólo ha sido encontrado en este sitio, y en algunos contemporáneos como Pavón en Pánuco, y hacia la zona de El Mante, Tamaulipas. Pero sigue siendo una cerámica escasa. En las colecciones locales no se tienen ejemplares completos, la mejor muestra es la recolectada por Ekholm en sus excavaciones de 1941, resguardada en el Museo de Historia Natural de Nueva York (Figura 8).

Los ejemplos más característicos son Las Flores Rojo sobre Ante, es decir el color natural de la superficie. Su decoración consiste en líneas rojas verticales, a veces en forma de grecas escalonadas sobre el cuerpo de las vasijas (Ekholm 1944: 392399), otras variantes son el Rojo y Negro sobre Ante, El Café Rojizo sobre Ante Claro y Rojo sobre Ante Claro; de los cuales existen pocos ejemplares (ídem). El tipo más característico son los Molcajetes Las Flores, tanto en pasta gruesa como fina. Se trata de cajetes semicirculares trípodes con el fondo interior esgrafiado geométricamente. Se presenta también una versión tardía del Zaquil Rojo (figura $8 \mathrm{~A}$ ), son cuencos trípodes usualmente con el exterior pintado de rojo desde el borde a la mitad de la vasija.

A este conjunto de cerámicas posiblemente de producción local, pero ajenas a la tradición cerámica de las fases anteriores, se agregan otros tipos de cerámicas 
foráneas, muy finas, como el blanco inciso, de origen desconocido; sin embargo, una vasija completa de este tipo fue hallada recientemente en Tula, Hgo. (Manuel Gamboa Cabezas, comunicación personal 2017) (figura $8 \mathrm{H}$ e I), indicando contemporaneidad y relaciones de Las Flores con Tula. Debido a que en la actualidad el área donde se ubica Las Flores está completamente urbanizada, ya es muy difícil recolectar nuevas muestras de cerámica.

\section{Fase Tamuín (1200-1550 d.n.e)}

\section{Negro sobre blanco}

Característica del periodo final de la Huasteca, hasta el contacto europeo, es la cerámica Negro sobre Blanco, a la cual Ekholm (1944: 364) se refiere como de una pasta que varía del grisáceo al naranja, con desgrasante muy fino. Es extremadamente dura y bien cocida. Las superficies decoradas, en ocasiones tienen un baño blanco grisáceo, o más frecuentemente crema, casi del mismo tono de la pasta. La superficie de las vasijas está bien pulida, pero el interior no, e incluso comúnmente presenta un baño de color rojo con tonalidades oscuras hasta el negro. Lo más característicos de esta cerámica es su decoración exterior, hecha con pintura negra que varía hasta tonos violeta rojizos. En ciertas formas de vasijas bajas, también el interior puede estar decorado. Sus diseños más usuales y básicos son bandas horizontales anchas, espaciadas, con pares de anchas líneas verticales separadas. También son frecuentes las volutas y las grecas escalonadas. (figura 9). Ekholm no conoció otros diseños más complejos que representan una iconografía muy elaborada que es frecuente en este tipo de cerámica como las 
cruces de San Andrés, los llamados ojos huastecos, caracoles cortados, signos del maíz o alas de mariposa, chalchihuites, puntos, etc. Este es el tipo de cerámica más abundante para los sitios postclásicos de nuestra zona de estudio.

\section{Tancol policromo}

Se trata como lo señala Ekholm (1944: 410) de la misma cerámica en pasta, forma y acabado, que el Negro sobre blanco; la diferencia radica en que algunos de sus diseños están pintados en blanco y negro, usando como relleno el rojo en tonalidades que varían hasta el violeta (figura 9G)

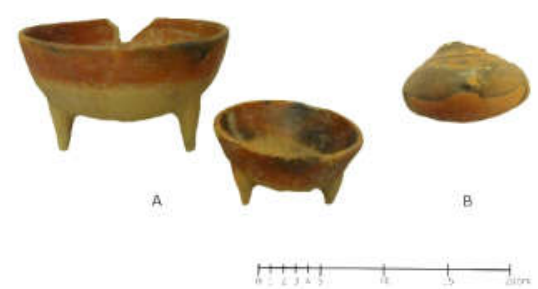

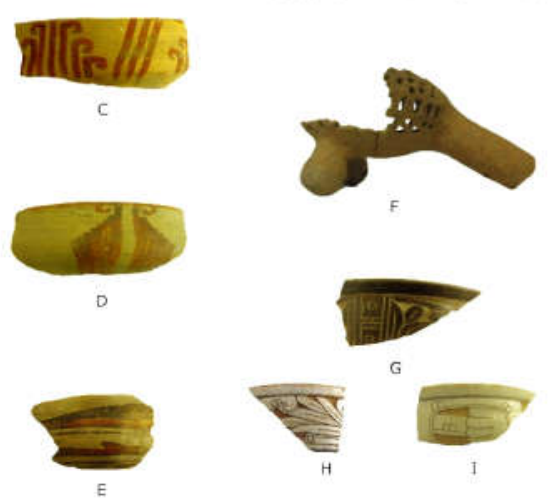

Figura 8. Cerámica tipo Las Flores. A) Molcajetes tipo Zaquil Rojo, B) cerámica Negros sobre Rojo C y D) tipo Rojo sobre Ante (Red on buff), E) Policromo. F) incensario. G, H, I) Cerámica Café incisa y Blanca Incisa. Todos los ejemplares proceden de las excavaciones de Ekholm en Las Flores (1944). Fueron fotografiados y reproducidos gracias a la cortesía del American Museum of Natural History de Nueva York. Elaboración propia con fotografía de Gustavo A. Ramírez (2008). 


\section{. \\ A

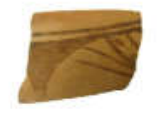

B

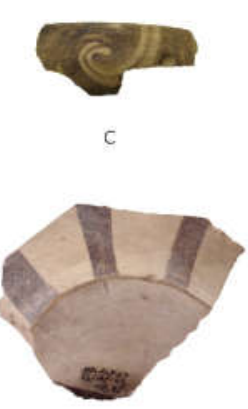

D
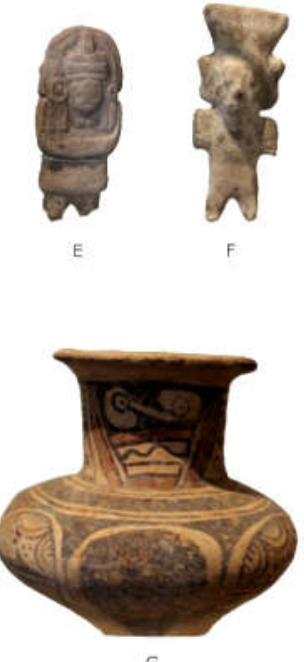

G

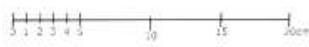

Figura 9. Cerámica Negro sobre Blanco y Tancol Policromo. A, B y C) Negro sobre blanco, procedente de La Gloria, municipio de González. D) fondo de olla procedente de Chak Pet, municipio de Altamira. E y F) tipo de figurillas generalmente asociadas a las cerámicas postclásicas de la Huasteca, procedencia desconocida (Museo de la Huasteca). G) Vasija Tancol Policromo, procedencia desconocida (Museo de la Huasteca). Elaboración propia con fotografía de Gustavo A. Ramírez. Piezas E, F y G, fotografiadas y reproducidas por cortesía del Museo de la Huasteca en Tampico, Tamaulipas, INAH.

\section{Contextos}

La caracterización de los asentamientos ha sido un tema central en la investigación arqueológica, y la Huasteca no es la excepción, aunque generalmente se han concentrado los esfuerzos en el patrón de asentamiento, como el ya referido estudio de Gutiérrez (1996). Otra forma de caracterización es la llamada Tipología de Sitios, propuesta por Gustavo A. Ramírez (2001, 2008b), desarrollada a partir de la necesidad de caracterizar los sitios de cazadores recolectores localizados en los salvamentos arqueológicos Río Escondido - 
Arroyo Coyote y Corindón -Reno Sur (ibídem: 26-27). La tipología se basa en el análisis de paisaje como contexto, que da indicios de las preferencias en el uso del espacio para ciertas actividades.

El paisaje o contexto considera el relieve asociado a geoformas locales, componentes geológicos, hidrológico, biológico o antrópico y su asociación a determinados artefactos o ecofactos que son indicadores de la actividad que se llevó a cabo en un asentamiento (ibídem: 45); así podemos encontrar, por ejemplo, que en los sitios de recolectores cazadores hay campamentos-taller, áreas de suministro, sitios rituales, etc.; y que los mismos se encuentran estrechamente ligados tipos específicos de paisajes que combinan dos o más rasgos de relieve o componentes como loma, llanura, montaña, laguna, río, arroyo, etc., y sus posibles combinaciones: loma/laguna, llanura/arroyo, montaña/lago, etc. Un ejercicio más extenso sobre la tipología de sitios para recolectores - cazadores del noreste mexicano es el de Valdovinos (2009), para la zona adyacente a la Presa Falcón en Tamaulipas.

La primera aplicación parcial de este modelo para la Huasteca es la tesis de Pamela Reza Martínez (2010), quien lo aplicó para un conjunto de 66 sitios ubicados sobre los trazos combinados con una extensión de $299 \mathrm{Km}$, de tres líneas de trasmisión eléctricas, en el norte de la Huasteca. A partir de los recorridos en nuestra área de estudio se plantea entonces una tipología que tiene sus propias y exclusivas características geomorfológicas, asociadas a actividades específicas. 
Para nuestro caso, los componentes geomorfológicos observados y sus combinaciones son:

a) Sierra: pequeña cordillera de no más de $200 \mathrm{~m}$ de altura correspondiente a la Sierra de la Palma, cuyas características ya fueron tratadas antes.

b) Cerro: elevación de tierra aislada de menor altura que la sierra (Real Academia española [RAE], 2018).

c) Colina: elevación natural del terreno, menor que una montaña (RAE 2018). En este caso una serie de elevaciones suaves que rodean la laguna de El Chairel, en Tampico.

d) Loma: una elevación de tierra de poca altura (entre 5 y $30 \mathrm{~m}$ para la zona) y prolongada (ídem).

e) Llanura: terreno plano, sin altos ni bajos (ídem).

f) Tierra Alta: porción de tierra elevada entre dos lagunas o entre una laguna y un río (Ramírez el al. 2018).

g) Isla: porción de tierra rodeada de agua (ídem).

h) Laguna: depósito natural de agua, dulce o salobre en la zona, menor que un lago (ídem).

i) Río: corriente de agua continua y caudalosa que desemboca en otra, un lago o el mar (ídem).

j) Marisma: terreno bajo y pantanoso inundado por las aguas del mar (ídem).

k) Las combinaciones presentes en los sitios hasta ahora localizados en nuestra zona de estudio se reducen a las siguientes: Cerro/Laguna; Colina/Laguna; Isla/laguna; Loma/llanura; Loma/marisma; Loma/laguna; Sierra, Sierra/venero; Tierra Alta/río; Tierra Alta/Laguna. 


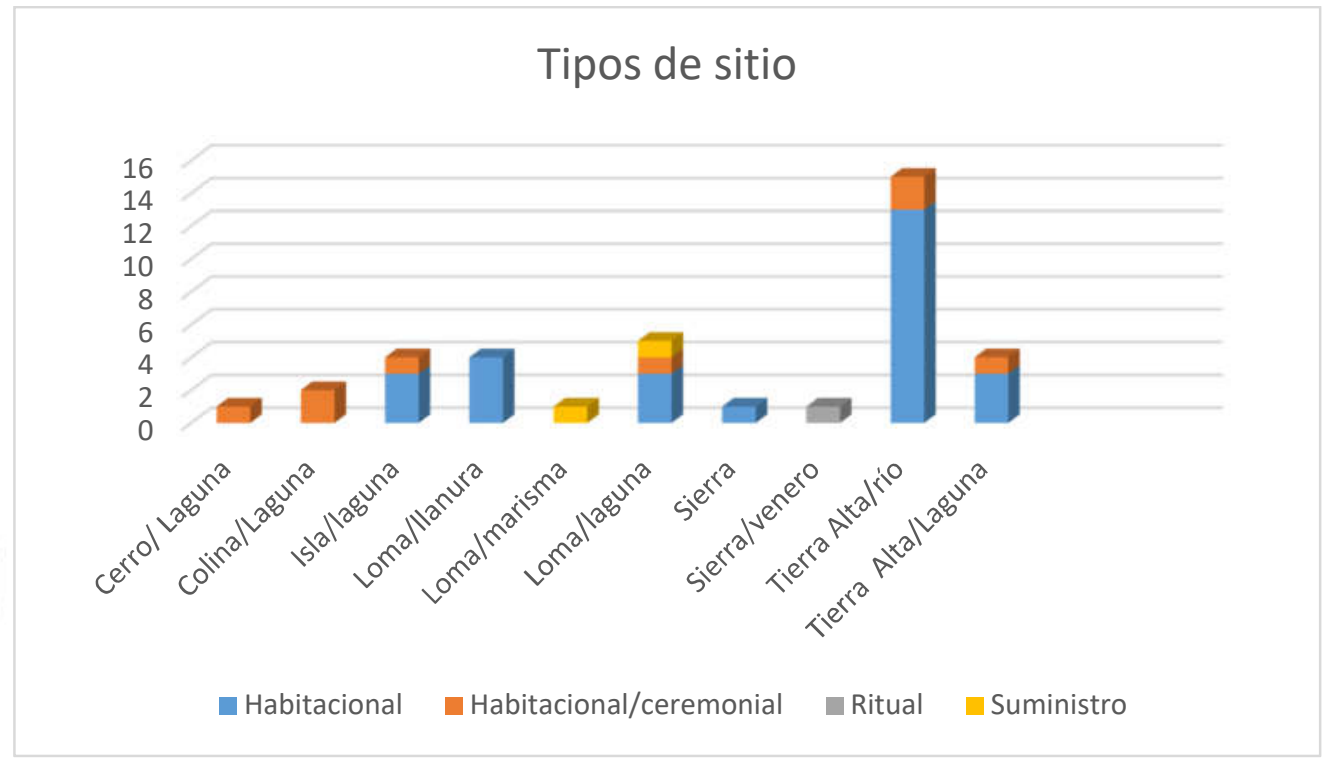

Figura 10. Tipos de sitio por contexto. Elaboración propia.

La figura 10 nos muestra que, de los 38 sitios registrados, la mayor parte de estos es de tipo habitacional y se ubicaron preferentemente en un terreno elevado situado entre el río Tamesí y una laguna, desde el Preclásico. Escasamente un par de sitios son a la vez habitacionales y ceremoniales, se trata de los sitios La Gloria y Tamos I, el primero es un sitio de gran extensión situado entre el río Tamesí y la laguna Salada, con presencia de montículos concentrados en un área central, aunque rebajados o demolidos por la población actual. Presenta una gran cantidad de materiales cerámicos, líticos y figurillas, algunos de origen o influencia mexica, secuela de la expansión de la Triple Alianza a la Huasteca entre los siglos XV y XVI. El segundo sitio, Tamos I, se ubicaba en donde actualmente se 
encuentra la subestación de la Comisión Federal de Electricidad (CFE). Anteriormente se observaban en la superficie grandes cantidades de cerámica Negro sobre blanco. La gente dice que había montículos que fueron demolidos durante la construcción de la subestación. Parece ser que Wilfrido Du Solier exploró este sitio en la década de 1940.

Sigue en preferencias el contexto de Loma/laguna, que es el patrón más recurrente en la zona durante el Preclásico. La mayor parte de los asentamientos son de tipo habitacional, situados sobre lomas alargadas naturales de entre 5 a $30 \mathrm{~m}$ de altura, junto a una laguna. En algunos casos, donde no había lomas naturales construyeron plataformas de tierra con la forma de una loma natural, donde asentaron su aldea; lo cual debió implicar un esfuerzo formidable.

Aunque para el postclásico este ya no fue un patrón preferente, hay al menos dos sitios que se ubicaron allí en ese periodo, que son de tipo habitacional y ceremonial, en uno de ellos, El Fuerte, se encontró una escultura fragmentada de un hombre sedente, en el estilo característicos de la escultórica huasteca, muy ancho y delgado. El otro, Salsipuedes, se sitúa en una pequeña península en la laguna La Tortuga, sobre la cual se distribuyen diversos montículos de tierra de baja altura. Un sitio interesante por ser de suministro es llamado Chapopotito, situado a poca distancia de lo que los vecinos llaman una chapopotera, brote natural de petróleo crudo, ampliamente usado en la antigüedad como pigmento, pegamento y aditivo en construcciones de tierra. 
Lo que pude observar fue en realidad un nacimiento de agua sulfurosa, alrededor de la cual hay una acumulación de azufre que también pudo ser aprovechado en tiempos prehispánicos. Sin mucha diferencia respecto al anterior, tenemos el contexto Tierra Alta/laguna, en donde claramente la preferencia es para sitios habitacionales durante el Preclásico y Clásico, y como habitacional y ceremonial durante el Postclásico, con un sitio destacado, que es el llamado propiamente Tierra Alta, situado en la colonia Manuel Cavazos Lerma de Tampico, a orillas de la laguna Champayán.

Este sitio ya ha sido objeto de exploraciones por Joaquín Meade en la década de 1940 y por Gustavo Ramírez, Carlos V. Pérez Silva y Sophie Marchegay entre 1999 y 2007 (ver Ramírez 2000, 2007), revelando la presencia de grandes montículos de tierra con pisos de cal y asfalto, el enterramiento ritual de dos mujeres (González Sobrino et al. 2004) con una rica ofrenda de oro, cobre, concha y un guajolote (Melleagris Gallopavo) sacrificado (Ramírez 2019, en prensa).

En el contexto Loma/llanura, tenemos asentamientos semejantes a los de Loma/río o Loma/laguna; con la excepción de que éstos se encuentran lejos de fuentes de agua, y por lo tanto presentan una innovación que es la excavación de jagüeyes, o depósitos artificiales de agua, algunos de los cuales aún se encuentran en funcionamiento. Los cuatro casos registrados abarcan todos los periodos del preclásico al Postclásico, lo que indica que fue un patrón exitoso que se mantuvo por miles de años, con apenas cambios. 
Del contexto Loma/marisma sólo se reporta un caso, pero es el más interesante. Corresponde al denominado sitio Chak Pet, cuyas exploraciones de salvamento durante más de una década revelan que es junto con Altamirano (HV-24), en Pánuco, Veracruz, el segundo más antiguo de la Huasteca. El sitio se ubica sobre una loma de 28 m.s.n.m., paralela a la costa, en cuya parte más baja hay una marisma. Esta marisma produce sal de manera natural; por lo que no es descabellado suponer que fue explotada por los antiguos habitantes de Chak Pet, desde el formativo medio. Las salinas, actualmente de Lomas del Real, fueron propiedad del rey de España y se han mantenido en operación hasta ahora, aunque menguadas por el crecimiento del puerto Industrial de Altamira.

Es este, por tanto, un sitio habitacional y de suministro de sal, producto que al parecer se intercambió por objetos suntuarios como finos pendientes de piedra verde, espejos de pirita y hematita, a grandes distancias, posiblemente hasta Costa Rica y Guatemala (Ramírez 2016). En la zona en torno a este sitio se han localizado doce sitios más, de los cuales uno fue campamento para la recolección furtiva de sal en la época Postclásica (Ramirez et al. 2007), y los demás aún están pendientes de explorar.

El contexto Colina/laguna es interesante; corresponde a las suaves elevaciones que rodean la laguna de El Chairel en Tampico, pero que incluso en ciertos puntos del borde de la laguna alcanzan hasta 30m de altura en acantilado. En dicha zona se asentaba el sitio llamado Las Flores, en la literatura arqueológica (ver Fewkes 
1906, Ekholm 1944, Ramírez 2000), del cual sólo se conserva un montículo conocido popularmente como la Pirámide de las Flores. Originalmente se componía por 22 montículos de tierra recubiertos con un grueso aplanado de calarena, un sistema constructivo único en la zona, cuyo único similar lo reportó el mismo Muir para el sitio Santa Fe, Veracruz (Muir 1926).

Los materiales de este sitio son peculiares, ajenos a la tipología local tradicional, Merino y García Cook lo ubica hacia los años 900 al 1200 d.C. fase Tamul (Merino y García 1989: 201), dentro del Posclásico temprano. Joaquín Meade reportó además el hallazgo de dos esculturas, una de las cuales representa a un hombre sedente y la otra una diosa madre (Meade 1942), sin embargo, existen serias dudas a que procedan de este sitio, pues su cronología es casi medio milenio posterior. No obstante, se puede admitir que el asentamiento, además de habitacional, fue ceremonial. El otro sitio es el llamado Tancol, que en el pasado debió ser enorme, pues cerámicas y enterramientos humanos se hallan frecuentemente en el panteón y colonias circunvecinas, aunque su núcleo, compuesto por doce montículos de tierra, es pequeño. Dicho núcleo se ubica actualmente dentro del Colegio Americano de Tampico, protegido por una cerca. Fue excavado por Ekholm (1944:405-418), quien reporta un antecedente de ocupación preclásica, pero su mayor auge fue Postclásico, caracterizado por su famosa cerámica Tancol Policromo, (figura 9G). 
Los siguientes contextos, más escasos, son Cerro/laguna, correspondiente al Cerro de la Campana, del periodo Postclásico, de carácter habitacional y ceremonial, y los llamados Sierra a secas, y Sierra/venero.

La sierra corresponde como ya se dijo a la Sierra de la Palma, una elevación muy interesante pues presenta diversos asentamientos prehispánicos, que no se habían conocido aún para la época del PCL. En todos ellos predominan elementos como la arquitectura de piedra, la presencia de esculturas o relieves con iconografía distintiva de la huasteca y la cerámica Negro sobre Blanco y Tancol Policroma (figura 9), lo que los ubica sin duda en la categoría de habitacionales y ceremoniales.

Aquí nos referimos específicamente al sitio La Palma, que como se indicó al inicio, fue descubierto por Alejandro Prieto (1975 [1873]) a fines del S. XIX. Este sitio tiene terrazas delimitadas con piedra, cimientos de construcciones cuadrangulares; y al menos un montículo o pirámide cónica truncada y revestida con piedra trabajada.

Sin embargo; otros sitios cercanos, como El Ojite y Microondas, muestran arquitectura similar, pero su diferenciación con respecto a los otros contextos es que éstos están en la sierra, alejados totalmente de las fuentes mayores de agua dulce, las lagunas más cercanas están a $6.5 \mathrm{~km}$ de distancia, mientras que el río Barberena se localiza a $30 \mathrm{Km}$ al noreste y casi la misma distancia al mar. 
Un caso especial es el contexto Sierra/venero; ya que se trata de la misma sierra, pero de un sitio ubicado justo en el punto donde nace un venero de agua, y que, dada la lejanía de las fuentes de agua dulce, ésta debió de tener una importancia crucial.

A escasos $30 \mathrm{~m}$ de donde nace el venero, cuesta arriba, se erigía vertical una estela labrada en una tosca laja de roca caliza, de $2.10 \mathrm{~m}$ de alto, por $3.52 \mathrm{~m}$ de ancho y $40 \mathrm{~cm}$ de espesor, que ahora está caída de frente sobre una piedra (figura 11), lo que permite apreciar dos cabezas de lagarto grabadas en su superficie; razón por lo que se le dio el nombre de Dos Lagartos (figura 12), una de las cabezas está fragmentada.

Vistos de perfil, los lagartos evocan el rostro de Tláloc, por lo que no es descabellado pensar que el monumento se erigió para consagrar el nacimiento de agua. El lugar carece de cualquier otro elemento arqueológico (Ramírez 2019, en prensa), Otro sitio recién descubierto, situado en el piedemonte, al que he llamado Caras Labradas, presenta un bloque de caliza labrado con rostros de diosas madres y unos cuencos con canales en la superficie superior, quizá para celebrar rituales dedicados al agua (ídem) como el anterior (figura 13). 

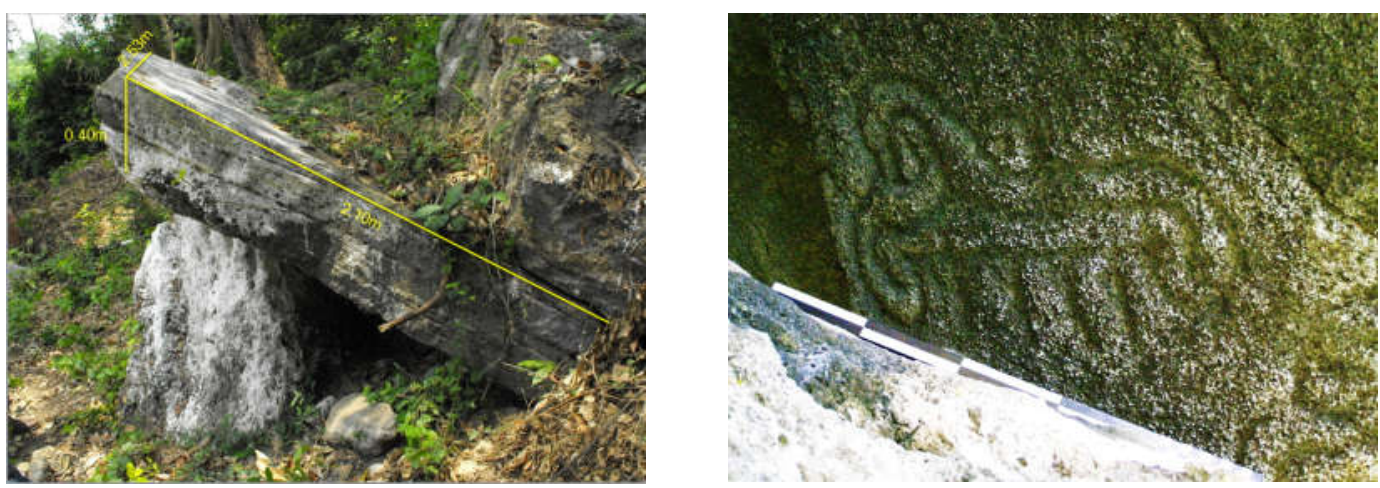

Figuras 11 y 12. Lápida de Dos Lagartos, sierra de La Palma, Altamira, Tams. Fotografía: autor 2008.

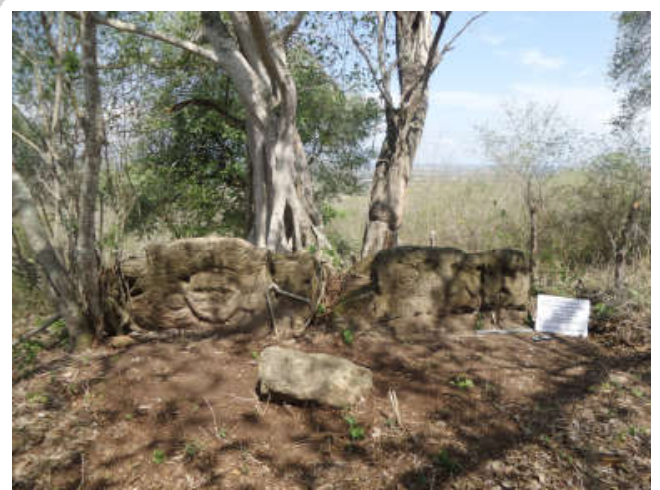

Figura 13. Sitio Caras Labradas, monolito con petrograbados que representan a las diosas de la fertilidad. Esteros, municipio de Altamira. Fotografía: autor 2018.

\section{Cronología}

La figura 14 nos ofrece una visión de cuáles fueron las preferencias en la ocupación del espacio a lo largo de la época prehispánica, para nuestra zona de estudio. Así se aprecia que, el contexto Tierra Alta/río fue el más utilizado en todos los periodos, con menor intensidad en el Preclásico y Clásico; pero con mayor frecuencia en el Postclásico. 


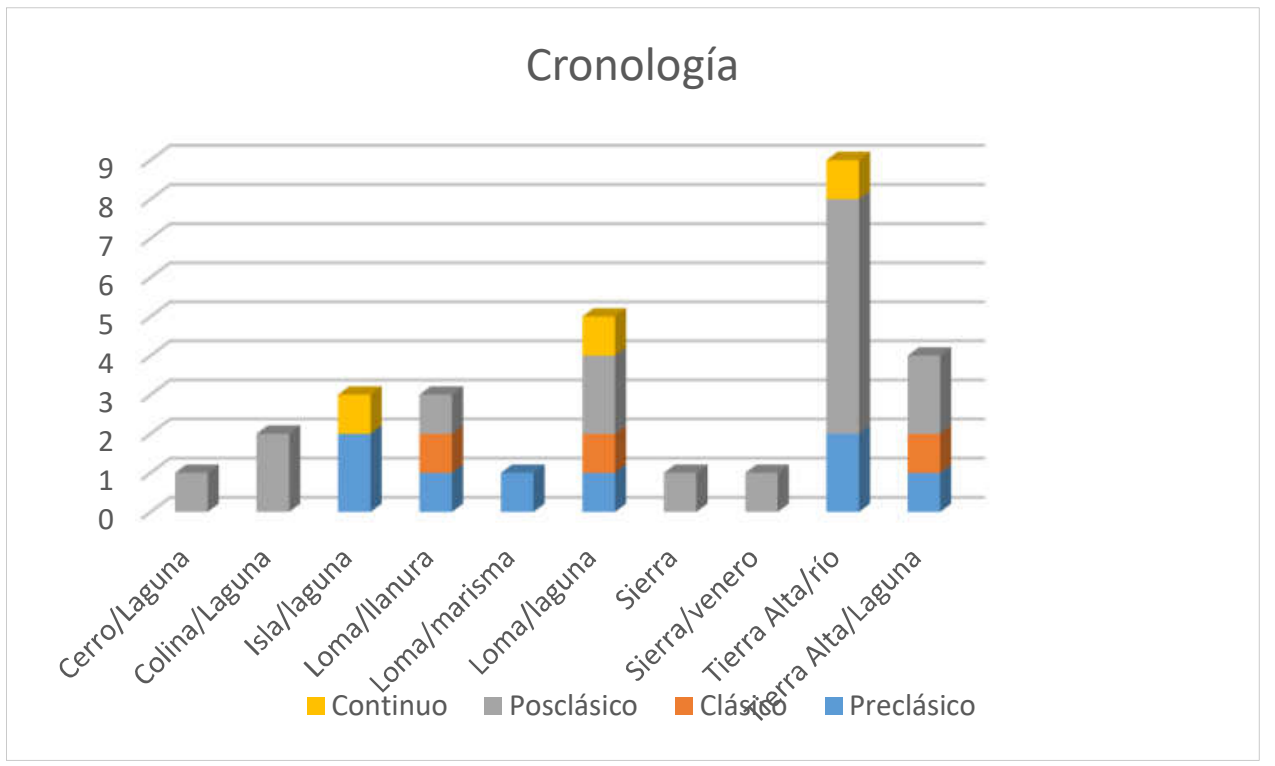

Figura 14. Cronología de los sitios por contexto y actividad. Elaboración propia.

Hay que destacar que los ríos no sólo ofrecen una abundante fuente de agua potable, sino que además proporcionan una gran cantidad de alimentos y materias primas, y son una vía de comunicación ventajosa mediante la navegación. Sin duda esta combinación de elementos de un terreno elevado y seguro contra las inundaciones, y los recursos fluviales, ofrecen las mayores ventajas para un asentamiento humano.

El mismo fenómeno se aprecia para el contexto Tierra Alta/laguna y Loma/laguna, que fueron aprovechado casi en las mismas proporciones durante 
todos los periodos. Las diferencias con el anterior es que las lomas naturales no son muy abundantes en esta planicie costera, y es necesario a veces edificarlas con un gran esfuerzo. Aun no queda claro si la necesidad de ocupar las lomas era por seguridad durante las crecidas del Pánuco, o si tiene una motivación ideológica relacionada con los mitos cosmogónicos. Por ejemplo, que el lomo del lagarto representa la tierra que flota en el mar (ver Ochoa y Gutiérrez 1996-1999, Ramirez 2008: 25). La laguna ofrece ventajas similares a las del río, aunque algunas lagunas eran saladas, hasta que se hicieron los diques para evitar la entrada del mar.

El contexto Loma/llanura también muestra preferencias de uso en todos los periodos, aunque en menor proporción, sobre todo por su lejanía de las fuentes agua. No obstante, este problema se solventó con la invención del jagüey, como ya se dijo antes.

Otro paisaje muy aprovechado, aunque limitando en cantidad es la Isla/laguna; pues, aunque hay muchas islas, pocas se pueden aprovechar verdaderamente debido a su bajo nivel sobre el agua. Hasta ahora los contextos registrados solo muestran ocupación del Preclásico, como en el caso de Mata del Muerto, donde se erigió una gran loma artificial sobre la margen oriental de la isla para ubicar el asentamiento humano. La isla de los Algodones en la laguna La Salada, es accesible a pie durante la seca. En el centro de la isla se yergue un gran cerro en cuya cúspide se adaptó el terreno para una aldea de grandes dimensiones. Dos 
enormes prominencias de tierra naturales pueden haber sido aprovechadas como montículos rituales, similares al Tizate o el paso del Bayo en Tamtok, S.L.P. (ver Stresser-Péan et al. 2005). Aunque su ocupación se dio durante el preclásico y los inicios del Clásico, se recuperaron fragmentos de lo que parece escoria de fundición de cobre; por lo que pudo haber sido reocupada en el Postclásico, pues está muy cerca del sitio la Gloria que, como se dijo, tiene influencia mexica. De las islas, la más sobresaliente es la Pitahaya, ubicada en la Laguna de El Chairel, frente a Tampico, cuya ocupación inició en el Preclásico y al parecer se prolongó hasta el Postclásico. La peculiaridad de esta isla es que tanto su suelo como su conjunto de montículos están hechos sólo de conchas de bivalvos y arena. Según Ekholm (1944:421) quien la exploró, dice que los montículos estaban rodeados por sendas lajas de piedra verticales, de lo cual queda poca evidencia.

Del contexto Loma/marisma hasta ahora sólo registramos un caso, el ya discutido de Chak Pet, cuya ocupación comenzó en el Preclásico medio y terminó en el Clásico temprano, con algunas incursiones furtivas de huastecos para tal vez recolectar sal durante el Postclásico, en una época en la que, al parecer, los recolectores-cazadores ya habían ocupado la planicie hasta la ribera del Pánuco, según lo refieren fuentes coloniales (Ramírez et al 2007).

Los contextos minoritarios como Colina/laguna, Cerro/laguna, Sierra y Sierra/venero, rebelan algo importante; dado que todos ellos sólo aparecen en el periodo Postclásico, se hace evidente que esta población no es local, ni tiene 
apego hacia las fuentes de agua; no obstante, comprende la importancia del líquido vital y lo sacraliza, al grado de erigir monumentos dedicados sus ritos.

\section{CONCLUSIONES}

Los análisis cerámicos muestran que con excepción de Chak Pet, cuyos orígenes se remontan al Preclásico medio, hacia el año 900 a.C., el resto de los sitios Preclásicos sólo muestran en superficie cerámicas Prisco, Pánuco Gris y Pánuco Pasta Fina que los sitúan entre los años 600 a.C. al 200 d.C., fases Tantuán I, Tantuán II y Tantuán III. Sólo unos pocos sitios muestran cerámicas del tipo Zaquil Negro y Zaquil rojo, como Isla de la Pitahaya, y tal vez el Chapopotito y Cúes de Palmas Altas, que indican una continuidad durante el Clásico medio al tardío, con una posible reocupación durante el Posclásico tardío, entre los años 900 al 1000 d.C.

Lo anterior revela que el inicio del poblamiento de la zona se dio durante el Preclásico temprano, con auge en el Preclásico tardío, es decir, durante al menos 800 años de una tradición continua en cuanto a conceptos, técnicas, estilos y patrones de ocupación, que fueron alterados hacia el 100 a.C., cuando una nueva población introduce las cerámicas Pánuco Pasta Fina y las figurillas estilizadas Pánuco $\mathrm{C}$, que representan un tipo físico diferente al de las fases anteriores. Sin embargo, un suceso aún no determinado interrumpió el poblamiento en el 200 d.C. La mayor parte de las aldeas fueron abandonadas. Unas pocas lograron 
sobrevivir hasta el siguiente periodo, alrededor del 400 d.C., cuando quedó definitivamente despoblada la región.

Hacia el 700 d.C., llegan nuevos pobladores. Éstos traen unas cerámicas muy diferentes a las anteriores, más relacionadas con el altiplano central, con Tula Xicocotitlán y posiblemente con Cholula; se asientan en Las Flores, cerca del agua, pero a una altura considerable para estar a salvo de las crecidas. Durante unos 300 años permanecen allí, pero con poco impacto hacia las zonas vecinas.

Es hasta los años 900 al 1000 d.C. que un nuevo contingente llega con fuerza, repoblando toda la región, particularmente la cuenca lacustre del Tamesí, rica en recursos naturales. La nueva población generalmente no ocupa los asentamientos ancestrales, sino que se asienta en zonas elevadas, tierras altas, cerros, colinas y especialmente en la sierra de La Palma, desarrollan sus destrezas en la talla de escultura, iconografía, arquitectura de piedra y despliegan un mundo de creencias cosmogónicas que dejan plasmadas en sus creaciones. Son los huastecos; pero ¿quiénes son, de dónde vinieron?

La evidencia colectada y nuestras interpretaciones coinciden en gran medida con lo observado y expuesto por Leonor Merino y Ángel García Cook $(1989,2004)$ para el desarrollo cultural de la Cuenca Baja del río Pánuco, que se resume a continuación: 
Fase Tantuán I (650-350 a.n.e.). Se inicia un florecimiento regional que fue incrementándose en Tantuán II (350 -100 a.n.e.) (García y Merino 2004: 21), presentándose un apogeo cultural del área, ocupándose una amplia zona territorial donde los pobladores se asentaron en lomas bajas alejadas de las fuentes de agua permanente como ríos, arroyos y lagunas. Lo mismo se aprecia en nuestra zona de estudio, con la diferencia de que las lomas bajas, ya sean naturales o artificiales, se situaban también junto a ríos y lagunas o frente al mar. El número de jagüeyes se multiplica (ídem) pero, al parecer, los jagüeyes sólo se cavaron en las lomas alejadas de las fuentes de agua, pero es un punto que debe corroborarse. De acuerdo con García Cook y Merino, el ajuar utilitario se multiplicó y se distribuyó en una región más grande, siendo el Prisco Negro uno de los tipos cerámicos más característicos, el cual se ha observado en asentamientos en Nuevo León, Tamaulipas, Veracruz y Tabasco, en Río Verde y Alaquines, S.L.P. (ibídem: 22), e incluso hasta Uaxactún y Kaminaljuyú en Guatemala, como lo he sugerido.

Fase Tantuán II (350 -100 a.n.e.) y Tantuán III (100 a.n.e. - 200 d.n.e), el apogeo regional llega a su máxima expresión (ibídem: 23), se multiplica el número de pueblos, que contienen varias estructuras en su zona cívico- religiosa, con una o más plazas de planta circular, una zona "residencial" con basamentos para casas entre 1 y 2 metros de altura y formando, en algunos casos, plazas circulares en el área residencial (ídem). Para la cuenca lacustre del Tamesí no observamos tal complejidad arquitectónica, los asentamientos se mantienen básicamente igual desde Tantuán I al III, es decir, lomas bajas de hasta 30 metros de altura, 
nivelados y con no más de tres montículos, aunque es usual que no tengan ninguno.

Hacia finales de Tantuán III, alrededor del año 100 d.n.e., se presenta una fuerte disminución de la población, el número de asentamientos disminuye drásticamente, como se observa para otras regiones de Mesoamérica (ibídem: 25). Al concluir Tantuán III, el norte y noroeste del área de estudio del P.A.H., se abandonó y se concentró hacia el sureste(ídem). Como ya se dijo, el mismo fenómeno se observa en la cuenca lacustre del río Tamesí, aunque a nuestro modo de ver, asociada también a la incursión de una nueva población que trae consigo la vajilla Pánuco Pasta Fina y las figurillas asociadas. Al parecer muy pocos asentamientos pudieron subsistir hasta el 400 d.C.

Finalmente, solo resta decir que este es un breve resumen de una mayor cantidad de información disponible, y que es necesario continuar el estudio y ampliarlo hacia la ribera sur del complejo lagunar, lo que sin duda permitirá ampliar y corregir nuestras observaciones. 


\section{REFERENCIAS BIBLIOGRÁFICAS}

CARBAJAL Tradacete, Francisco Javier; Juan Ángel Sánchez de Llanos, José Luis González Buerdiel, Óscar del Río Benito, Juan Gonzalbo Navarro, Francisco Javier García Moral y David Gutierrez Iglesias. Hidrología del Río Pánuco. The Nature Conservacy, p. 1-51, 1994. Recuperado de: http://famm.mx/wp-content/pdf/capitulo2hidrologia-del-panuco.pdf

Carranza-Edwards, A., M. Gutiérrez y R. Rodríguez. Unidades morfotectónicas continentales de las costas mexicanas. Anuario Centro de Ciencias del Mar y Limnología, Universidad Nacional Autónoma de México., 2(1), p.81-88, 1975.

CASTAÑEDA Cerecero, Laura Adriana. La cerámica del Formativo en la cuenca baja del Pánuco, en: El Preclásico o Formativo, Avances y Perspectivas. Coord. Martha Carmona Macías. Museo Nacional de Antropología. INAH, México, 1989.

Altamirano un sitio Formativo al noreste de México, Tesis de profesional, Escuela Nacional de Antropología e Historia, México, 1992.

CONAGUA. Actualización de la disponibilidad media anual de agua en el acuífero Zona Sur (2813), Estado de Tamaulipas. Diario oficial de le Federación, p. 1-28, 20 de abril, 2015. Recuperado de:

https://www.gob.mx/cms/uploads/attachment/file/104435/DR 2813.pdf

DOMÍNGUEZ Rodríguez, Irán Roxana, La Lítica de la Planicie Costera de Tamaulipas, Tesis profesional, Escuela Nacional de Antropología e Historia, México, 2009.

EKHOLM, Gordon F. Excavations at Tampico and Panuco in the Huasteca, Mexico. Anthropologist Papers of the National Museum of Natural History, Vol. XIII (1). 1944.

FEWKES, Jesse Walter. Certain antiquites of Eastern Mexico. Twenty -fiftth annual report of the Bureau of American Ethnology. Smithsonian Institution. Washington, 1907.

FRANCISCO Martínez, Argelia, La Actividad Física de los Antiguos Pobladores de Chac Pet, Altamira, Tamaulipas, Tesis de Licenciatura, Escuela Nacional de Antropología e Historia, Posgrado en Antropología Física, México, 2016. 
GARCÍA Cook, Ángel y Beatríz L, Merino Carrión. Secuencia cultural para el formativo en la cuenca baja del río Pánuco. Arqueología (32), INAH, México, p. 5-27. 2004.

GARCÍA, E. Modificaciones al Sistema de Clasificación Climática de Kopen. Instituto de Geografía. Universidad Nacional Autónoma de México, 4ta. Ed. México, 1988.

GARCÍA Payón, José, Prehistoria de Mesoamérica. Excavaciones en Trapiche y Chalahuite, Veracruz, México, 1942, 1951 y 1959. Universidad Veracruzana, 1966.

GONZÁlEZ Sobrino, Blanca Z., Gustavo A. Ramírez Castilla y Carlos Serrano Sánchez. Osteología de un notable enterramiento prehispánico huaxteco, proveniente de Tierra Alta, Tampico, Tamaulipas. Prácticas funerarias en la Costa del Golfo de México. Yamile Lira López y Carlos Serrano Sánchez, Editores. Universidad Veracruzana. UNAM. AMAB, 2004.

GUTIÉRREZ Mendoza, Gerardo. Patrón de asentamiento y cronología en el sur de la Huaxteca: Sierra de Otontepec y laguna de Tamiahua. Tesis profesional. Escuela Nacional de Antropología e Historia. México, 1996.

HURTADO Baker, S.J. El gran humedal de la planicie del Río Tamesí. Región de la desembocadura del río Pánuco. $4^{\circ}$ Congreso de Investigación en Cambio Climático. Universidad Autónoma de Tamaulipas, 2014. Recuperado de: http://www.pincc.unam.mx/4tocongreso/sedes html/TAMAULIPAS\%204CNICC2014/ susana hurtado baker.pdf

LANKFORD, R. Coastal Lagoon of México. Their origin and Classification. In: M. Wiley (Ed), Estuarine Processes, Academic Press., 2:182-215, 1977.

MACNEISH, Richard. An early archaeological site near Panuco, Vera Cruz. Transactions of the American Philosophical Society, vol. 44, parte 5. Philadelphia, 1954.

MEADE Trápaga, Joaquín. La Huasteca, época antigua. Publicaciones Históricas. Editorial Cossío. México, 1942. 
MERINO Carrión, Beatriz Leonor y Ángel García Cook. Proyecto Arqueológico Huaxteca . Arqueología. No. 1. INAH. México, p. 31-72. 1989.

Definición del formativo en la cuenca baja del río Pánuco, Primer informe. Archivo Técnico del INAH, México.

MUELLERIED, K.G. Algunas observaciones sobre los “cúes” en la Huasteca. El México Antiguo.

Tomo 2. México., p. 20 - 29, 1924.

MUIR, Jhon. Data on the structure of Pre - Columbian Huastec Mounds in the Tampico region, Mexico. The Journal of the Royal Anthropological Institute of Great Britain and Ireland. Vol. 56. London, p. 231- 238, 1926.

OCHOA, Lorenzo y Gerardo Gutiérrez.1996-1999. Notas en torno a la cosmovisión y religión de los Huaxtecos. Anales de Antropología, (33). IIA-UNAM. México, p. $91-$ 163.

PRIETO, Alejandro. Historia, geografía y estadística del Estado de Tamaulipas. Edición facsimilar de la de 1873. Porrúa, México, 1975.

SELER, Eduard. Die Alten Ansiedelungen im Gebiete der Huasteca, Berlín, 1888.

STRESSER-PÉAN, Guy y Claude Stresser-Péan. Tamtok, sitio arqueológico Huasteco. CEMCA-El Colegio de San Luis-Instituto de Cultura de San Luis PotosíCONACULTA -INAH, México, 2001.

TOUSSAINT, Manuel. La conquista de Pánuco. Ediciones de El Colegio Nacional. México, D.F. 1948.

RAMÍREZ Castilla, Gustavo A. Informe Técnico del salvamento arqueológico L.T. Tamós -Pánuco, Veracruz, Archivo Técnico del INAH, México, 1997.

Informe técnico del rescate arqueológico Tierra Alta,

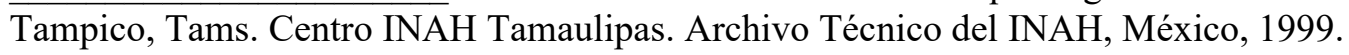


Las Flores: historia de un sitio arqueológico de la Huasteca Tamaulipeca. Instituto Tamaulipeco para la Cultura y las Artes. Ciudad Victoria. 2000.

Informe técnico del rescate arqueológico Tancol, 1999. Archivo Técnico del INAH, México, 2000b

El entierro doble de Tierra Alta, Tampico, Tamaulipas. Arqueología Mexicana (47), 68-71. 2000c

Una propuesta tipológica para sitios arqueológicos del Noreste de Informe técnico parcial del salvamento arqueológico L.T. Puerto AltamiraChampayán. Archivo Técnico del INAH, México, 2001.

Rescate arqueológico Champayán-Anahuac-Potencia, 2001. Archivo Técnico del INAH, México, 2002.

México.

Salvamento Arqueológico Río Escondido - Arroyo Coyote

(Tramos Tamaulipas - Nuevo Léon - Coahuila). Informe técnico parcial. Vol. 1. Archivo Técnico del INAH, México, 2003.

Costumbres funerarias en la cuenca lacustre del Pánuco. Prácticas funerarias en la Costa del Golfo de México. Yamile Lira López y Carlos Serrano Sánchez, Editores. Universidad Veracruzana. UNAM. AMAB. 2004.

Panorama Arqueológico de Tamaulipas. Programa de Estímulos a la Creación y al Desarrollo Artístico de Tamaulipas, Gobierno del estado de Tamaulipas, Instituto Tamaulipeco para la Cultura y las Artes, 2007.

Asentamientos Prehispánicos de la Cuenca Lacustre del Tamesí - Pánuco, Proyecto. Archivo Técnico del INAH, México, 2006.

Asentamientos Prehispánicos de la Cuenca Lacustre del Tamesí - Pánuco, Proyecto. Primer Informe Técnico Parcial. Archivo Técnico del INAH, México, 2007b. 
Asentamientos Prehispánicos de la Cuenca Lacustre del Tamesí - Pánuco, Proyecto. Segundo Informe Técnico Parcial. Archivo Técnico del INAH, México, 2008.

Propuesta Tipológica de Sitios Arqueológicos para el Noreste de México", Memoria del Primer Coloquio Internacional del Noreste Mexicano y Texas, Juana Gabriela Román Jaquéz (Coord). INAH, México, 2008b.

Loma Real-Chak Pet, un village préhispanique sur la côte spetentrionale de la Huasteque, les Huaxteques, Peuple Méconnu du Mexique Précolombien, Catalogue de l'Exposition, Sophie Marchegay, Mussé du Prehistoire des Gorges du Verdon, Quinson, Alpes de Haute-Provence, France, p. 71- 82, 2016.

A Turkey Sacrificed as an Offering for an Elite Woman in Tierra Alta, Northern Huasteca in Mexico. AD 1200-1500 (en prensa) 2019.

Petrograbados para rituales del agua en la Sierrita de la Palma, Huasteca Septentrional (en prensa) 2019b.

RAMÍREZ Castilla, G. A., Román Güemes Jiménez, Artemio Arroyo Mosqueda, y Manuel Pérez Zeballos, J. M. De aquí somos, La Huasteca. Consejo Nacional para la Cultura y las Artes, Programa de Desarrollo Cultural de la Huasteca, 2008.

Asentamientos Prehispánicos de la Cuenca Lacustre del Tamesí - Pánuco, Proyecto. Archivo Técnico del INAH, México, 2007.

Asentamientos Prehispánicos de la Cuenca Lacustre del Tamesí - Pánuco, Proyecto. Archivo Técnico del INAH, México, 2007.

Ramírez Castilla, G.A y Sophie Marchegay, Proyecto de Salvamento Arqueológico Puerto de Altamira, Tamaulipas. Archivo Técnico del INAH, México, 2007.

Informe técnico parcial del Salvamento Arqueológico Puerto de Altamira, Tamaulipas. Archivo Técnico del INAH, México, 2008 . 
RAMÍREZ Castilla, G.A, Sophie Marchegay, Sixto Rodríguez Rosas, y Héctor Pérez García. Rescate arqueológico Lomas del Real, Puerto Altamira, Tamaulipas, sitio No. 2, Polígono API 2, Fracción A1. Archivo Técnico del INAH, México, 2007.

RAMÍREZ Castilla, G. A., Tonantzin Silva Cárdenas y Jesús E. Velasco González, Arquitectura Prehispánica de Tierra en la Cuenca Lacustre de los Ríos Tamesí y Pánuco. En A. J. Daneels (coord.)., La Arquitectura de Tierra en Mesoamérica, Instituto de Investigaciones Antropológicas, UNAM, 2018.

RATTRAY Childs, Evelin. La Cerámica de Teotihuacan: relaciones externas y cronología. Anales de Antropología (16), UNAM. Pp. 51-70, 1979.

ROLÓN Aguilar, Julio César; Sergio Jiménez Hernández, Roberto Pichardo Ramírez y Juana Treviño Trujillo. Programa de gestión del agua del río Guayalejo-Tamesí, Informe Técnico. Comisión de Cuenca del Río Guayalejo-Tamesí. Gerencia Operativa, 2012.

SILVA Cárdenas, Tonantzin Bienbenida, Mismos Espacios, Diferentes Paisajes. La API-Altamira: Sitios Arqueológicos, Históricos y El Puerto de Gran Calado, Tesis de Licenciatura, Escuela Nacional de Antropología e Historia, México, 2010.

VALDOVINOS Pérez, Víctor Hugo, Entre manos y pies. Prácticas funerarias en el norte de la Huasteca, formativo terminal, Tesis de posgrado en estudios Mesoamericanos, UNAM, México, 2018.

ZARAGOZA Ocaña, Diana M. La Huasteca siglos XV y XVI, propuesta de subáreas culturales, Tamohi como estudio de caso. Tesis Doctoral. IIA-UNAM. 